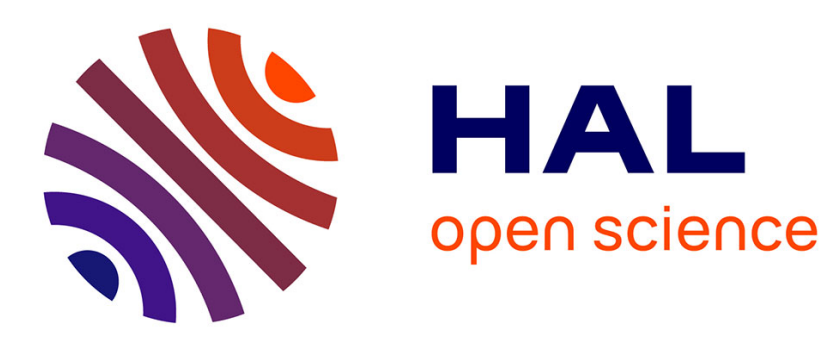

\title{
Addition of Sulfenic Acids to Monosubstituted Acetylenes: a Theoretical and Experimental Study
}

Alessandro Contini, Maria Chiara Aversa, Anna Barattucci, Paola Bonaccorsi

\section{To cite this version:}

Alessandro Contini, Maria Chiara Aversa, Anna Barattucci, Paola Bonaccorsi. Addition of Sulfenic Acids to Monosubstituted Acetylenes: a Theoretical and Experimental Study. Journal of Physical Organic Chemistry, 2009, 22 (11), pp.1048-n/a. 10.1002/poc.1557 . hal-00477799

\section{HAL Id: hal-00477799 https://hal.science/hal-00477799}

Submitted on 30 Apr 2010

HAL is a multi-disciplinary open access archive for the deposit and dissemination of scientific research documents, whether they are published or not. The documents may come from teaching and research institutions in France or abroad, or from public or private research centers.
L'archive ouverte pluridisciplinaire HAL, est destinée au dépôt et à la diffusion de documents scientifiques de niveau recherche, publiés ou non, émanant des établissements d'enseignement et de recherche français ou étrangers, des laboratoires publics ou privés. 


\section{Journal of Physical Organic Chemistry}

WILEY

\section{Addition of Sulfenic Acids to Monosubstituted Acetylenes: a Theoretical and Experimental Study}

\begin{tabular}{|r|l|}
\hline Journal: & Journal of Physical Organic Chemistry \\
\hline Manuscript ID: & POC-08-0252.R2 \\
\hline Wiley - Manuscript type: & Research Article \\
\hline Date Submitted by the & O2-Mar-2009 \\
\hline Complete List of Authors: & $\begin{array}{l}\text { Contini, Alessandro; Università degli Studi di Milano, Istituto di } \\
\text { Chimica Organica } \\
\text { Aversa, Maria; Università degli Studi di Messina, Dipartimento di } \\
\text { Chimica organica e biologica } \\
\text { Barattucci, Anna; Università degli Studi di Messina, Dipartimento di } \\
\text { Chimica organica e biologica } \\
\text { Bonaccorsi, Paola; Università degli Studi di Messina, Dipartimento } \\
\text { di Chimica organica e biologica }\end{array}$ \\
\hline Keywords: & syn-Addition, DFT, HSAB principle, Regioselectivity, Sulfenic acids \\
\hline &
\end{tabular}

\section{(s) ScholaroNE" \\ Manuscript Central}




\title{
Addition of Sulfenic Acids to Monosubstituted
}

\section{Acetylenes: a Theoretical and Experimental Study}

\author{
Maria Chiara Aversa, ${ }^{1,3}$ Anna Barattucci, ${ }^{1,3}$ Paola Bonaccorsi ${ }^{1,3}$ and Alessandro Contini ${ }^{2,3} *$ \\ ${ }^{1}$ Dipartimento di Chimica organica e biologica, Università degli Studi di Messina, Salita Sperone 31 \\ (vill. S. Agata), 98166 Messina, Italy \\ ${ }^{2}$ Istituto di Chimica organica “A. Marchesini”, Facoltà di Farmacia, Università degli Studi di Milano, \\ Via Venezian 21, 20133 Milano, Italy. \\ ${ }^{3}$ Centro Interuniversitario di Ricerca sulle Reazioni Pericicliche e Sintesi di Sistemi Etero e \\ Carbociclici \\ alessandro.contini@unimi.it \\ Tel. +390250314480 \\ Fax +390250314476
}

\begin{abstract}
The reaction of benzenesulfenic acid, generated in situ by thermal decomposition of 3(phenylsulfinyl)propanenitrile, with monosubstituted acetylenes was experimentally and theoretically investigated at the DFT level using the MPW1B95 density functional. A computational model based on the Hard Soft Acid Base (HSAB) principle was evaluated for its ability to qualitatively and
\end{abstract}


quantitatively predict the regioselectivity, while kinetics and thermodynamics of the reaction were studied through the analysis of the reaction paths leading to the possible regioisomers.

\section{Introduction}

The importance of sulfenic acids $\mathrm{RSOH}$ as transient intermediates in biological processes is widely recognized. Oxidation of thiol groups in living systems and much of the chemistry of the penicillin sulfoxides have been considered to involve sulfenic acids. ${ }^{[1]}$ Unfortunately, most of them are too unstable to be isolated and, for this reason, much of the knowledge of their reactions has been derived indirectly through the rationalization of the final products. In particular, the syn-addition of sulfenic acids to carbon-carbon triple bonds provides an easy way to obtain vinyl sulfoxides in mild conditions and with some regioselectivity, and this reaction has found several applications in organic synthesis. ${ }^{[2]}$ Some theoretical works concerning the chemistry of sulfenic acids were carried out, most of them dealing with the mechanism of the sulfoxide thermolysis, through the combination of theoretical calculations with instrumental analysis. ${ }^{[3]}$ Another computational study compared the syn-elimination from corresponding amine oxides, sulfoxides, and phosphine oxides, showing that the elimination from an amine oxide occurs with the lowest activation barrier, with the sulfoxide being the intermediate case. ${ }^{[4]}$ Other works were found dealing with the mechanism of sulfoxide reduction by thiols ${ }^{[5]}$ with the rearrangement of $\mathrm{H}_{2} \mathrm{SO}$ to give sulfenic acid $\mathrm{HSOH}^{[6]}$ or studying the acidity of several inorganic sulfur oxoacids. ${ }^{[7]}$ Concerning the syn-addition of sulfenic acids to carbon-carbon multiple bonds (Scheme 1) the generally accepted reaction mechanism is concerted and, when the sulfenic acid is trapped by a monosubstituted unsaturated compound, the product is usually the one in which the partial positive charge deriving from $\mathrm{H}$ approach to the multiple bond is better stabilized at the TS level, thus the Markovnikov or anti-Markovnikov products for electron-donor (ED) or electron-withdrawing (EW) substituents. $^{[8]}$ 
Markovnikov

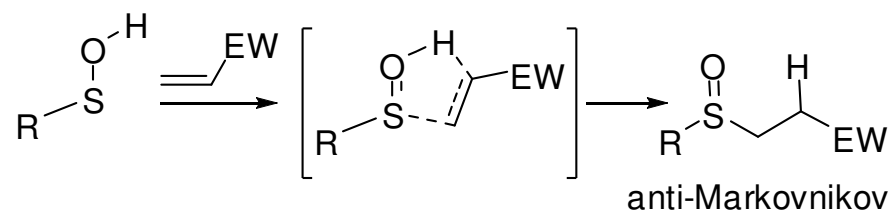

\section{Scheme 1.}

To our knowledge, the syn-addition reaction of sulfenic acid to carbon-carbon triple bonds has never been subjected to a systematic computational study. In particular, we were interested in rationalizing the role of the alkyne substituent in governing the regiochemical outcome as well as in identifying some reliable computational models able to predict the regiochemistry. Starting from the excellent work of Jenks and coworkers, ${ }^{[3 \mathrm{~d}]}$ we have optimized a DFT based approach to study the addition between benzenesulfenic acid and alkynes. Indeed, within the DFT framework, the development of a simple theoretical model for the qualitative and semi-quantitative prediction of the addition regiochemistry has been also possible through the HSAB principle ${ }^{[9]}$ thus assisting in rationalizing the role of the alkyne substituent. Moreover, the computational analysis of the reaction paths leading to the different regioisomers and the comparison of theoretical and experimental results have provided new and interesting insights into the mechanism, kinetics and thermodynamics of the sulfenic acid syn-addition reactions.

\section{Results and Discussion}

Experimental test set. Some representative examples for evaluating the regiochemistry of the addition were planned in order to cover the main electronic and steric features of the alkyne substituent (Scheme 2). Thus, acetylenes bearing an aromatic strong or weak ED group (3a and $\mathbf{3 b}$ respectively), a phenyl substituent (3c), an aromatic strong EW group (3d), an aliphatic EW group (3e), and a sterically encumbered weak ED group (3f) were reacted with benzenesulfenic acid, generated in situ through the 
thermal decomposition of 3-(phenylsulfinyl)propanenitrile (1) (alkyne/1 molar ratio 6:1). Sulfenic acid precursor 1 has been obtained in two simple steps from benzenethiol. ${ }^{[10]}$ The reactions were conducted both in toluene and in acetonitrile at their reflux temperature in order to evaluate solvent influences in governing the regiochemical outcome. Yields have been almost quantitative in all the cases.

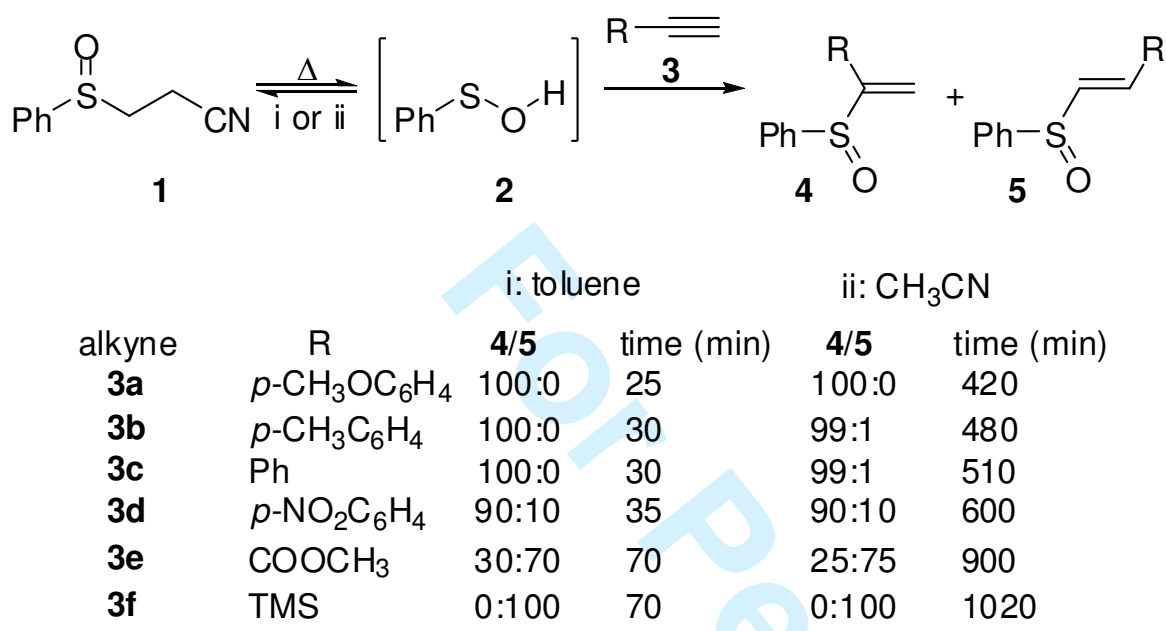

Scheme 2 (Reaction time and products obtained by the addition of sulfenic acid $\mathbf{2}$ to alkynes $\mathbf{3}$ ).

Results reported in Scheme 2 suggest that the solvent plays no relevant action in ruling the regiochemistry, because an apolar solvent such as toluene and a polar aprotic solvent such as acetonitrile lead essentially to the same regioisomeric ratio. The main observed change concerns the reaction time, much shorter when the addition is conducted in toluene (from 25 to $70 \mathrm{~min}$ for $\mathbf{3 a}$ and $\mathbf{3 e}, \mathbf{f}$, respectively). Bearing in mind that the reaction is conducted at reflux, the observed differences in reaction kinetics are probably due to the higher boiling point of toluene, and not to specific solvent effects. It should also be noted that, as suggested by calculation results extensively discussed later on, in most cases the reaction rate limiting step seems to be the decomposition of $\mathbf{1}$ to give benzenesulfenic acid $\mathbf{2}$, with the evident exception of alkyne $\mathbf{3 f}$ whose addition to $\mathbf{2}$ results as the rate limiting step.

Optimization of the theoretical method. The thermolysis of alkyl sulfoxides was theoretically and experimentally studied by Jenks and coworkers, ${ }^{[3 \mathrm{~d}]}$ who did a comparison of several levels of theory 
with experimental activation and reaction enthalpies. DFT calculations, performed with the B3LYP functional, ${ }^{[1]}$ led to poor results in terms of activation barriers, typically several kcal/mol too low in comparison with experimental or high level calculation results. Indeed, despite its wide use, the B3LYP functional is not recommended for reactions involving proton transfers. ${ }^{[12]}$ Very accurate results, in terms of reproduction of experimentally derived energy values, were obtained from MP2/6$311+\mathrm{G}(3 \mathrm{df}, 2 \mathrm{p}) / / \mathrm{MP} 2 / 6-31 \mathrm{G}(\mathrm{d}, \mathrm{p})$ calculations, thus this method was our first choice for studying the addition of sulfenic acids to alkynes. Unfortunately, preliminary calculations showed that this level of theory was too computationally demanding for our purposes. Indeed, starting from the B3LYP/6$31 \mathrm{G}(\mathrm{d}, \mathrm{p})$ optimized geometry, the optimization of the TS for the addition of benzenesulfenic acid (2) to phenylacetylene (3c) at the MP2/6-31G(d,p) level took more than seven days to converge on a recent quadcore computer. A less CPU intensive model was needed, since the high demand of frequency calculations, essential for thermochemistry evaluations, and the need to study several reaction paths. DFT appeared a reasonable choice, combining a proper treatment of electron correlation with a reasonably low computation time. ${ }^{[13]}$ Therefore we decided to evaluate some of the recent density functionals developed by the Truhlar group, namely the MPW1B95, MPWB1K, TPSS1KCIS, MPW3LYP and MPWKCIS1K, ${ }^{[14]}$ for their ability to reproduce both the experimental activation barriers and the geometries obtained by high level calculations. All calculations were performed with the $6-31+\mathrm{G}(\mathrm{d}, \mathrm{p})$ basis set for all atoms except sulfur, where additional $d$ functions are recommended for a proper treatment of its electronic structure. ${ }^{[15]}$ The thermolyses of the sulfoxides $\mathbf{a}$ and $\mathbf{b}$ (Scheme 3) were then used for the optimization of the theoretical model.

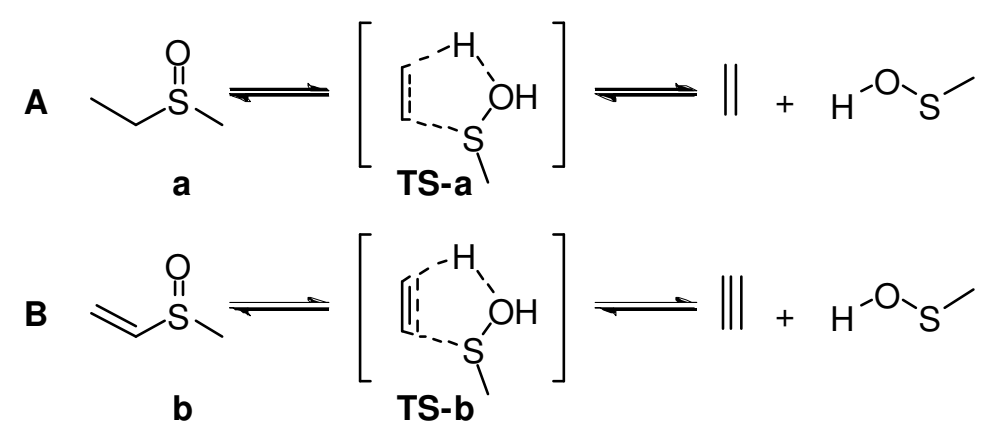


Scheme 3. Reaction models used for density functional evaluation.

Activation enthalpies resulting from the different methodologies were compared with those experimentally obtained, while the most important geometrical parameters of reactants $\mathbf{a}$ and $\mathbf{b}$ and the corresponding TSs were compared with the MP2/6-311+G(3df,2p) geometries through a regression analysis. As shown in Table 1, the overall best performance was obtained with the MPW1B95 and TPSS1KCIS density functionals, with slightly better results for the first method. MPW1B95/6$31+\mathrm{G}(\mathrm{d}, \mathrm{p}), \mathrm{S}(3 \mathrm{df})$ geometries are shown in Figure 1, where MP2/6-311+G(3df,2p) values are also reported for comparison.

Table 1. Performance of different density functionals in respect to experiments or MP2 calculations.

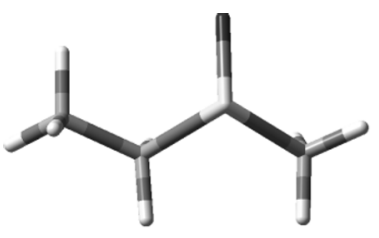

a

C-S: $1.81(1.80)$

C-H: $1.09(1.09)$

S-O: $1.48(1.49)$

C-C: 1.52 (1.52)

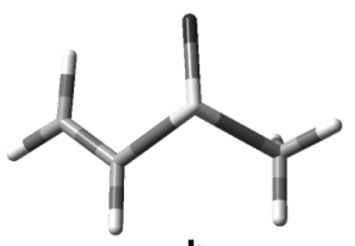

C-S: $1.77^{\mathbf{b}}(1.78)$

C-H: 1.08 (1.08)

S-O: $1.48(1.49)$

C-C: 1.33 (1.33)

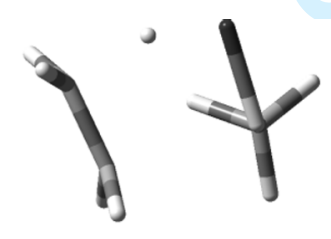

TS-a

C-S: 2.34 (2.33)

C-H: $1.41(1.42)$

S-O: 1.55 (1.57)

C-C: 1.40 (1.40)

$\mathrm{O}-\mathrm{H}: 1.19(1.17)$

$\mathrm{C}-\mathrm{H}-\mathrm{O}: 154.2$ (153.4)

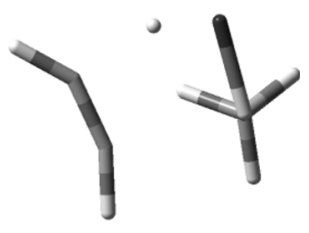

TS-b

C-S: $2.34(2.33)$

C-H: 1.56 (1.48)

S-O: $1.57(1.57)$

C-C: 1.25 (1.25)

O-H: 1.08 (1.13)

C-H-O: 149.9 (150.1)

Figure 1. MPW1B95/6-31+G(d,p),S(3df) optimized reactants and TSs for the thermolysys of sulfoxides a and $\mathbf{b}$, with MP2/6-311+G(3df,2p) values in parenthesis. ${ }^{3 \mathrm{~d}}$ Distances are reported in angstroms, angles in degrees. 
In order to esteem the basis set effects on the energies and geometries, all the stationary points were re-optimized at the MPW1B95/6-311+G(3df,2p) level. The activation enthalpies of reaction models A and $\mathbf{B}$ decreased by 0.5 and $1.6 \mathrm{kcal} / \mathrm{mol}$, respectively, and no relevant changes were observed in geometries. Almost the same energetic results $\left(\Delta H^{\ddagger}=31.6\right.$ and $42.0 \mathrm{kcal} / \mathrm{mol}$ for models $\mathbf{A}$ and $\mathbf{B}$, respectively) were obtained by performing single point calculations at the MPW1B95/6-311+G(3df,2p) level, thus justifying the use of the lighter basis set for geometry optimizations.

HSAB model. DFT, by adopting the electron density $\rho$ as the central quantity, provides an excellent tool for the theoretical study of chemical systems at a reasonable computational cost. Indeed, several chemical concepts can be precisely defined in the framework of the conceptual DFT, ${ }^{[16]}$ and quantities such as the chemical potential, electronegativity, hardness and softness actually correspond to the linear responses of $\rho$ with respect to changes in external potential $(v)$ and number of electrons $(N)$. Relevant reactivity indexes are the electron chemical potential $\mu=(\delta E / \delta N)_{v(\mathbf{r})}$, which measures the escaping tendency of electrons ( $E=$ molecular energy), and the softness $S=(\delta N / \delta \mu)_{v(\mathbf{r})}$, which describes the propensity of the molecule to gain or lose electrons as a response to a change in $\mu .^{[16 \mathrm{a}]}$ The above indexes are tied to the chemical reactivity through the HSAB principle, which is in turn deeply rooted in DFT. As our objective was to study the regioselectivity, an atomic reactivity index was needed and the best suited for this purpose was the local softness $s(\mathbf{r})=(\delta \rho(\mathbf{r}) / \delta \mu)_{v(\mathbf{r})}$, which describes the sensitivity of $\rho$ at the point $\mathbf{r}$ to a variation of $\mu .^{[16 a]}$ The local softness actually corresponds to the Fukui function $f(\mathbf{r})$, defined by Parr and Yang, ${ }^{[17]}$ multiplied by the global softness $S$ and contains the same information as Fukui functions plus additional information about the total molecular softness. As $\rho(\mathbf{r})$ is a discontinuous function of $N$, within the finite difference approximation and expressing $f(\mathbf{r})$ in the condensed form, three local softness indexes can be obtained for each atom in the molecule: $s^{+}$for its reactivity toward nucleophiles, $s^{-}$for electrophiles and $s^{0}$ for radicals, ${ }^{[18]}$ and the reaction is favored between atoms having similar $s$ values. Thus, in accordance with the local HSAB principle, ${ }^{[19]}$ a regioisomer is favored when the new bonds are formed between atoms with equal softness. 
Local softness values, calculated for the atoms involved in the addition of benzenesulfenic acid (2) to alkynes 3a-f and reported in Table 2, show that alkynes 3a-d are more reactive toward electrophiles at the unsubstituted carbon, where the sulfenic acid proton will be driven leading to a Markovnikov-like addition product, as generally observed for the $s y n$-addition reactions of sulfenic acids. ${ }^{[8]}$ On the other hand, in methyl propiolate (3e) the C-R carbon bears an $s^{-}$value higher than $\mathrm{C}-\mathrm{H}$, which is also characterized by a particularly high $s^{+}$, suggesting that the addition of benzenesulfenic acid will lead to an anti-Markovnikov product as the major regioisomer, in accordance with the experimental findings. The highest $s^{-}$value computed for the $\mathrm{C}-\mathrm{H}$ in alkyne $\mathbf{3 f}$ could suggest the Markovnikov product as the major regioisomer when benzenesulfenic acid is reacted with trimethylsilylacetylene, in net discordance with the experimental findings. However, as the general accepted mechanism of the syn-addition of sulfenic acids to multiple bonds is concerted, the simultaneous fulfillment of local HSAB principle at all the reaction centers should be considered. To this end, an expression which measures such fulfillment in a least square sense has been proposed for cycloaddition reactions, ${ }^{[20]}$ and we applied it to the addition reaction of 2 to 3a-f (see Table $2 ; \Delta_{4}$ and $\Delta_{5}$ are referred to the Markovnikov and anti-Markovnikov regioisomers, respectively). Considering that the smaller the value of $\Delta$ the greater is the extent that the HSAB principle is satisfied, our results reported in Table 2 are in perfect concordance with the experiments and this suggests that the HSAB principle is a valuable tool also to get preliminary insights into the reaction mechanism. Moreover, it's interesting to note that the HSAB model not only provided a correct regiochemistry prediction for entries $1-4$, where the same result could be obtained by simply applying the Markovnikov's rule, but also for the more trivial entry 5 where, being the alkylsylyl group a weak ED, the Markovnikov's rule would have had predicted the wrong regioisomer.

Table 2. Local softness computed for atoms involved in the addition of $\mathbf{2}$ to $\mathbf{3 a - f},{ }^{\mathrm{a}}$ HSAB fulfilment degrees $\Delta_{4}$ and $\Delta_{5}$, chemical potential differences $\Delta \mu_{2-3}(\mathrm{eV})$, and differences in grand potential variation $\Delta \Delta \Omega_{R 1-R 2}(\mathrm{~kJ} / \mathrm{mol})$. $^{\mathrm{b}}$ 
It was recently reported that, within the HSAB theory, quantitative regioselectivity predictions could also be made by calculating the variation $\Delta \Omega$ in the grand potential. ${ }^{[21]}$ Indeed, it is assumed that when two reactants approach each other the interaction occurs between pairs of atoms located in different molecules, and charge is transferred within such pairs in the very first step of the bond-forming interaction between the specific atoms. Such transfer equalizes the electron chemical potential and induces a variation $\Delta \Omega$ of the grand potential (that is the natural thermodynamic quantity describing the behavior of the reactants atoms, which are open subsystems freely exchanging energy and electrons) of the system. For concerted reactions, the difference $\Delta \Delta \Omega$ between two regioisomers is expected to be proportional to the energy difference between their TSs thus enabling a quantitative prediction without the need to locate the TSs, as reported by several successful examples. ${ }^{[22]}$ We then decided to apply this strategy by calculating $\Delta \Omega$ for each regioisomer, according to equations (1) and (2):

$$
\begin{aligned}
& \Delta \Omega_{4}=-1 / 2\left(\mu_{2}-\mu_{3}\right)^{2} \cdot\left(\frac{s_{H} s_{C H}}{s_{H}+s_{C-H}}+\frac{s_{S} s_{C-R}}{s_{s}+s_{C-R}}\right) \\
& \Delta \Omega_{5}=-1 / 2\left(\mu_{2}-\mu_{3}\right)^{2} \cdot\left(\frac{s_{H} s_{C-R}}{s_{H}+s_{C-R}}+\frac{s_{S} s_{C-H}}{s_{S}+s_{C-H}}\right)
\end{aligned}
$$

The obtained results, collected in Table 2, are in linear relationship with the activation energies $\Delta \Delta E^{\ddagger}$ obtained from the experimental ratio 4:5 through the Arrhenius equation, with the only exception of methyl propiolate (3e) which behaves as an outlier. The difference in activation energy for the two regioisomers 4 and 5 was obtained as $\Delta \Delta E^{\ddagger}=-R T \cdot \ln (\mathrm{Y})$, where $T$ is the reaction temperature $(383.6 \mathrm{~K}$ for toluene) and $\mathrm{Y}$ is the experimental ratio of 4:5. Analogously, the ratio 4:5 can be predicted from computed activation energies as $\mathrm{Y}=\mathrm{e}^{(\mathrm{Ea5}-\mathrm{Ea} 4) / \mathrm{RT}}$. Indeed, a least-square linear regression results in $\Delta \Delta \Omega$ $=0.02 \cdot \Delta \Delta E^{\ddagger}+0.30$ with a correlation coefficient $r^{2}=0.99$ only if the value computed for $3 \mathbf{e}$ is excluded. This could be due to secondary interactions at the TS level, which alter the value of $\Delta \Omega$ in a way that cannot be predicted by calculations on the isolated reactants (see the Computational analysis of the reaction paths section). However, our impression is that some attention should be paid when quantitative predictions are searched through $\Delta \Delta \Omega$ calculations, since a quantitative prediction can only 
be made through a linear regression analysis which provides the actual relationship between $\Delta \Delta \Omega$ and $\Delta \Delta E^{*}$. Indeed, by analyzing some of the examples reported in the literature, ${ }^{[22 \mathrm{a}, \mathrm{c}, \mathrm{d}]}$ it can be observed that the weighted linear regression equations are rather different from case to case. This means that a proper experimental "training set" should be prepared for each specific study, thus limiting the applicability of this valuable method to those problems well covered by experimental examples.

Computational analysis of the reaction paths. The main power of the local HSAB model is that predictions can be made by performing simple calculations on the isolated reactants only, without the need to localize all the TSs. However, this step is absolutely necessary for a through analysis of the reaction mechanism. For example the exceptionally high value of $\Delta \Delta \Omega$ obtained for the reaction of methyl propiolate $(\mathbf{3 e})$ remains unclear. Indeed, on the basis of the local softness computed for $\mathbf{3 e}$, the Markovnikov product $4 \mathbf{e}$ should not be obtained. Moreover, theoretical consideration on the reaction kinetics and thermodynamics can only be made by localizing all the stationary points along the potential energy surface (PES). Finally, the geometrical analysis of TSs can elucidate important aspects of the reaction mechanism, such as the synchronicity degree. For those reasons, all the TSs and products for the two regioisomeric paths of the reaction of $\mathbf{2}$ with $\mathbf{3 a - f}$ were located and optimized at the same level of theory discussed above. Activation free energies are collected in Table 3, where differences between the two regioisomeric paths $\mathbf{4}$ and $\mathbf{5}$ are also reported for clarity.

Table 3. Activation and reaction free energies (kcal/mol) for the addition of $\mathbf{2}$ to $\mathbf{3 a - f}$, and activation and reaction free energy differences $(\mathrm{kcal} / \mathrm{mol})$ between regioisomers $\mathbf{4}$ and $\mathbf{5}^{\text {a }}$

The mechanism of decomposition of sulfoxide $\mathbf{1}$ was also investigated in order to qualitatively evaluate the possibility for the reaction of benzenesulfenic acid 2 with alkynes 3a-e to compete with the reverse reaction of $\mathbf{2}$ with acrylonitrile. Results are graphically depicted in Scheme 4, where activation and reaction free energy ranges are also reported. 


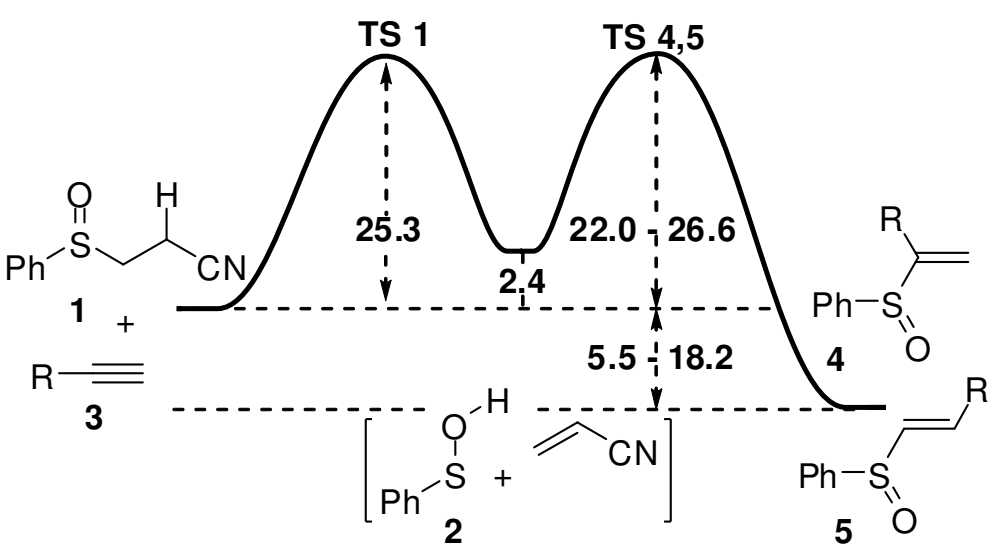

Scheme 4. Representation of the potential energy surface for the thermal decomposition of $\mathbf{1}$ on presence of alkynes 3. Activation and reaction free energy differences are reported in $\mathrm{kcal} / \mathrm{mol}$.

The decomposition of $\mathbf{1}$ to give $\mathbf{2}$ and acrylonitrile occurs through an activation barrier $\Delta G^{\ddagger}=25.3$ and appears to be slightly endothermic $(\Delta G=2.4)$. Keeping the sum of the energies of $\mathbf{1}$ and $\mathbf{3}$ as the reference, the activation barriers for the step leading to the isolable products $\mathbf{4}$ and $\mathbf{5}$ ranges from 22.0 $\mathrm{kcal} / \mathrm{mol}$ (computed for the addition of $\mathbf{2}$ to $\mathbf{3 e}$ to give $4 \mathbf{e}$ ) to $26.6 \mathrm{kcal} / \mathrm{mol}$ (obtained for the addition of $\mathbf{2}$ to $\mathbf{3 f}$ to provide $\mathbf{4 f}$ ). With the exception of $\mathbf{3 e}$, where a quite low $\Delta G^{\ddagger}$ was obtained due to the strong EW group $\mathrm{COOCH}_{3}$ which lowers the activation barriers, ${ }^{[3 \mathrm{~d}]}$ the competition of the addition of benzensulfenic acid $\mathbf{2}$ to alkynes $\mathbf{3}$ with the reverse reaction bringing back to $\mathbf{1}$ appears to be possible due to the very low $\Delta \Delta G^{\ddagger}$ between the two processes. Indeed, the addition of $\mathbf{2}$ to $\mathbf{3 a}$ to give $\mathbf{4 a}$ is favored over the reaction of 2 with acrylonitrile by only $0.6 \mathrm{kcal} / \mathrm{mol}$. An even lower difference was computed for $\mathbf{3 b}, \mathbf{c}(0.3 \mathrm{kcal} / \mathrm{mol})$ and for $\mathbf{3 d}(0.1 \mathrm{kcal} / \mathrm{mol})$, accordingly to the different electronic effect exerted by the aromatic substituent. For alkyne $\mathbf{3 f}$ a considerably higher activation barrier is observed and competition with the reverse reaction is considerable. Indeed the step leading to product $\mathbf{5 f}$ is kinetically unfavored with respect to the reverse reaction by $1.2 \mathrm{kcal} / \mathrm{mol}$, evidently due to the TMS substituent steric encumbrance which considerably raises the activation barrier. The steric hindrance of the TMS group is even more evident in the Markovnikov TS-4f (see Figure 2) which in fact was never isolated in the adopted experimental conditions. 


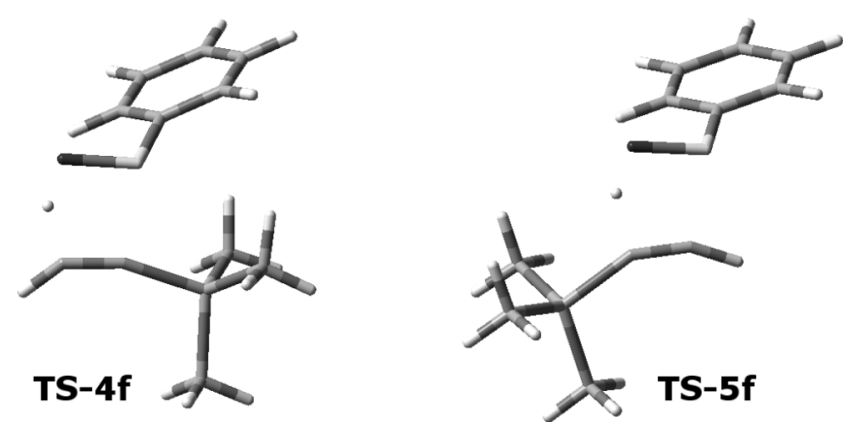

Figure 2. Optimized TS-4f and TS-5f.

It can also be observed that the reaction times (see Table 1) are in a general linear dependence with the computed activation barriers, but, once again, methyl propiolate (3e) behaves as an outlier having the lowest activation barrier $\left(\Delta G^{\ddagger}=22.9\right.$ and $22.0 \mathrm{kcal} / \mathrm{mol}$ for TS-4 and TS-5, respectively) with the longest reaction time (70 $\mathrm{min}$ when reacted in toluene). This suggests that some other chemical equilibrium may play a role in the addition of sulfenic acids to methyl propiolate. Indeed, the local HSAB analysis for compounds 3a-d,f showed that the highest $s^{-}$value, which distinguishes the most nucleophilic atom, is obtained for the alkyne $\mathrm{C}-\mathrm{H}$. The early stage of the addition reaction will be thus characterized by the formation of a complex between the phenylsulfenic acid $\mathbf{2}$ and alkynes 3a-d,f which will be closely related to the corresponding TSs. Otherwise, the highest $s^{-}$value for compound $\mathbf{3 e}$ is observed on the carbonyl oxygen $\left(\mathrm{s}_{\mathrm{O}=\mathrm{C}}^{-}=1.08\right)$ meaning that, in this case, a reactant complex $(\mathrm{RC})$ structurally unrelated with the addition TS can be formed by the non-covalent interaction of the carbonyl oxygen with the sulfenic acid hydrogen. To support this hypothesis, the early stage RC for the reaction of phenylsulfenic acid $\mathbf{2}$ with either alkyne 3a or alkine 3e were obtained through a reverse Intrinsic reaction coordinates (IRC) analysis starting from TS-4a and TS-5e, respectively, followed by full optimization. To be sure that the lowest energy complexes where obtained, different conformations were also optimized and compared. The most favored geometries are represented in Figure 3. 


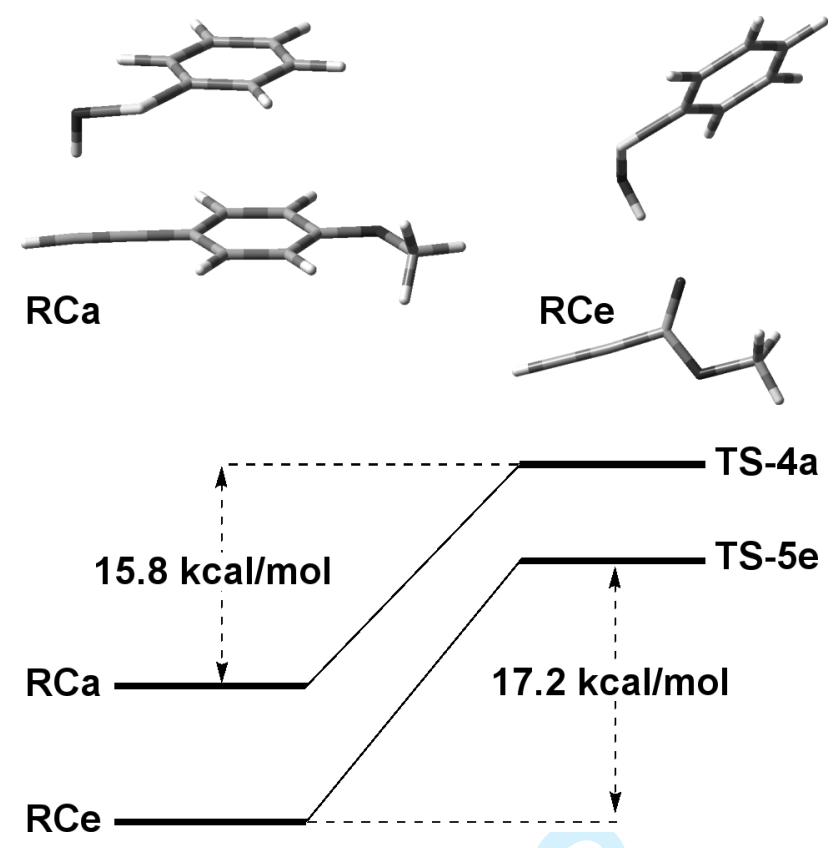

Figure 3. Reactant complexes obtained between 2 and 3a (RCa) or 3e (RCe) and free energy barriers between RCs and corresponding TSs

The visual inspection of the obtained complexes shows that the geometry of RCa closely resembles the corresponding TS-4a structure, while RCe converged to a structure which is far away from the TS geometry (similar results were obtained starting from either TS-4e or TS-5e) and is characterized by a hydrogen bond between the acidic sulfenic acid hydrogen and the carbonyl oxygen, as predicted by the HSAB analysis. The free energies calculated for both complexes resulted higher than those associated to the sum of the free energies of the isolated reactants 2 and 3a,e, but a $\Delta G$ of $6.4 \mathrm{kcal} / \mathrm{mol}$ was obtained for RCa, while a $\Delta G$ of $2.4 \mathrm{kcal} / \mathrm{mol}$ was computed for RCe. This means that, by considering the $\Delta G$ of the RC as the reference, a $\Delta G^{\ddagger}$ of $15.8 \mathrm{kcal} / \mathrm{mol}$ would be necessary for the conversion of $\mathbf{R C a}$ in the corresponding TS-4a, while a $\Delta G^{\ddagger}$ of $17.2 \mathrm{kcal} / \mathrm{mol}$ would be required to go from $\mathbf{R C e}$ to TS-5e, thus justifying the striking differences in reaction time. Different hypotheses of competing reactions were also thoroughly considered, but both computational results and chemical logic agreed in suggesting the above explanation as the most convincing.

Coming back to the main question of the reaction regiochemistry, useful information can be obtained through the activation and reaction free energy differences $\Delta \Delta G^{\ddagger-5}$ and $\Delta \Delta G_{4-5}$, respectively. Indeed, for 
the first three terms 3a-c the energy barrier leading to the Markovnikov products 4 is about $3 \mathrm{kcal} / \mathrm{mol}$ lower than the one calculated for products $\mathbf{5}$, which in fact were never experimentally obtained. The $\Delta \Delta G^{\ddagger}$ between TS-4d and TS-5d drops to $1.4 \mathrm{kcal} / \mathrm{mol}$, and as a consequence traces of product $(E)-1-(4-$ nitrophenyl)-2-(phenylsulfinyl)-ethene (5d) can be expected. The opposite is observed for $\mathbf{3 e}$, where the anti-Markovnikov product $5 \mathbf{e}$ is kinetically favored over $4 \mathbf{e}$ by $0.9 \mathrm{kcal} / \mathrm{mol}$, and for $3 \mathbf{f}$ where the $\Delta \Delta G^{\ddagger}$ raises to $2.5 \mathrm{kcal} / \mathrm{mol}$ in favor of the anti-Markovnikov TS-5f. The ratios between 4 and 5 were calculated from the above mentioned energy differences through the Arrhenius equation, and compared with experimental results through a regression analysis.

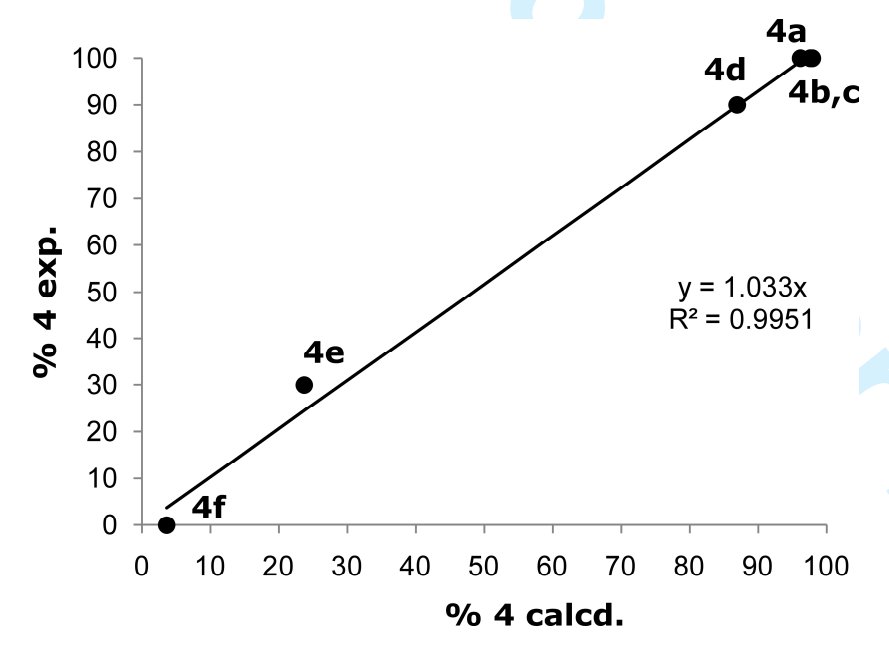

Figure 4. Predicted vs experimental percentage of regioisomers 4.

As depicted in Figure 4, the linear correlation between computed and experimental ratios is excellent $\left(\mathrm{r}^{2}\right.$ $=0.995)$ and this fact, while strengthening the adopted computational method, suggests that the regiochemical outcome is completely under kinetic control even if the reactions are performed under reflux conditions. Indeed, the anti-Markovnikov regioisomers 5 are the thermodynamic products, being from 1.3 to $2.7 \mathrm{kcal} / \mathrm{mol}$ more stable than the corresponding products 4 , but a kinetic-thermodynamic competition cannot be expected in the adopted conditions due to the high activation barriers of the reverse reactions. The geometrical and vibrational analysis of the optimized stationary points and IRC 
analyses, reported in Figure 5, confirm that the reactions studied herein are concerted, in concordance to the generally accepted mechanism. ${ }^{[8]}$
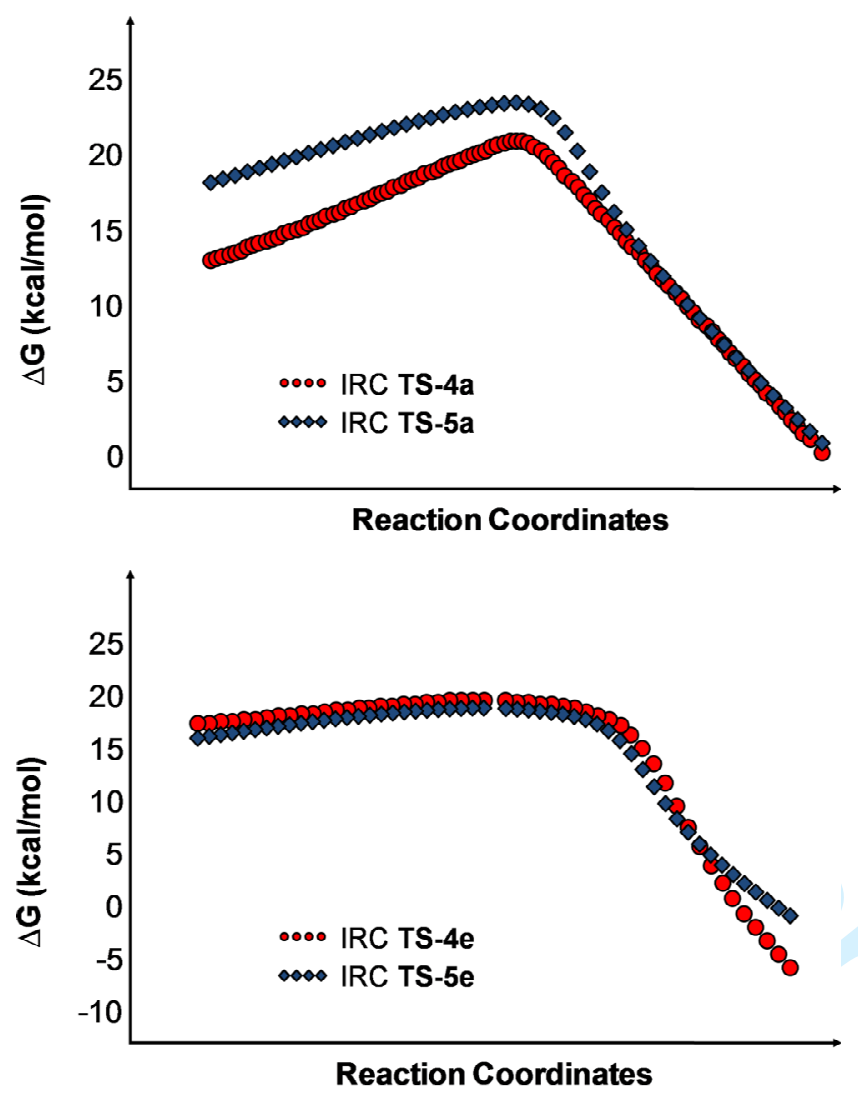

Figure 5. IRC calculations for the reactions of $\mathbf{2}$ with $\mathbf{3 a}$ and $\mathbf{3 e}$ at MPW1B95/6-31+G(d,p),S(3df). Relative energies are referred to the energy of the isolated reactants.

Table 4 reports selected Bond Order Indexes (BOIs) obtained from the Natural Bond Orbital (NBO) analysis of the optimized stationary points, ${ }^{[23]}$ which can be compared in order to gain information about the "earliness" or "lateness" of TSs, as well as to evaluate the general synchronicity of the examined reactions. The computed values for the S-O bond in products confirms the ylide character of sulfoxides, as previously observed by Jenks and by Sundberg and Molina through an Atoms-in-Molecules analysis. $^{[3 \mathrm{~d}, 24]}$ 
Table 4. Selected Wiberg Bond Order Indexes (BOIs). ${ }^{a}$ BOI differences between the forming bonds in TSs are reported in parenthesis.

The inspection of BOIs calculated for the C-H and C-S bonds in TSs reveals that all reactions follows a quite synchronous mechanism, although syn-additions leading to products 4 result slightly more synchronous than the corresponding path $\mathbf{5}$, where the sulfur addition on the unsubstituted alkyne carbon foregoes the protonation step. The difference between BOIs $\left(\triangle_{B O I}\right)$ of the two forming bonds, which can be taken as a measure of synchronicity, ranges from 0.02 to 0.18 (TS-4f and TS-4e, respectively) for path 4, while values between 0.14 and 0.28 (TS-5a,b and TS-5e, respectively) are obtained for path 5, with the addition of methyl propiolate being the most asynchronous in both cases. This is quite surprising, as opposite relationships between the synchronicity and the electronic character of the $\mathrm{R}$ substituent can be observed for paths 4 and $\mathbf{5}$. Indeed $\Delta_{B O I}$ raises from 0.03 to 0.08 by switching from TS-4d $\left(\mathrm{R}=p-\mathrm{NO}_{2} \mathrm{C}_{6} \mathrm{H}_{4}\right)$ to TS-4a $\left(\mathrm{R}=p-\mathrm{CH}_{3} \mathrm{OC}_{6} \mathrm{H}_{4}\right)$ and an even more evident dependence seems to exist for path 5 with a $\Delta_{B O I}$ of 0.14 , obtained for TS-5a,b $\left(\mathrm{R}=p-\mathrm{CH}_{3} \mathrm{OC}_{6} \mathrm{H}_{4}\right.$ and $p-\mathrm{CH}_{3} \mathrm{C}_{6} \mathrm{H}_{4}$, respectively), which raises to 0.28 and 0.30 for $\mathbf{T S - 5 e}\left(\mathrm{R}=\mathrm{COOCH}_{3}\right)$ and $\mathbf{T S}-5 \mathbf{d}\left(\mathrm{R}=p-\mathrm{NO}_{2} \mathrm{C}_{6} \mathrm{H}_{4}\right)$, respectively. Generally, it can be concluded that ED substituents, while favoring the Markovnikov like TS-4, increase the reactions asynchronicity by anticipating the protonation step, as the C-H BOI is slightly closer to its final state than the C-S. Contrarily, EW substituents favor the anti-Markovnikov like TS-5 and increase the asynchronicity by anticipating the nucleophilic attack of the $S$ atom, as confirmed by $\mathrm{C}-\mathrm{S}$ BOI higher than $\mathrm{C}-\mathrm{H}$. The peculiar behavior of methyl propiolate (also observed in the HSAB analysis where product $4 \mathbf{e}$ resulted decidedly unfavored, in net disagreement with the experimental evidences) is still unclear. However, a singularity consisting in an attractive weak hydrogen interaction possible for TS-4e but not for TS-5e was revealed by the analysis of the TSs geometries, depicted in Figure 6. 

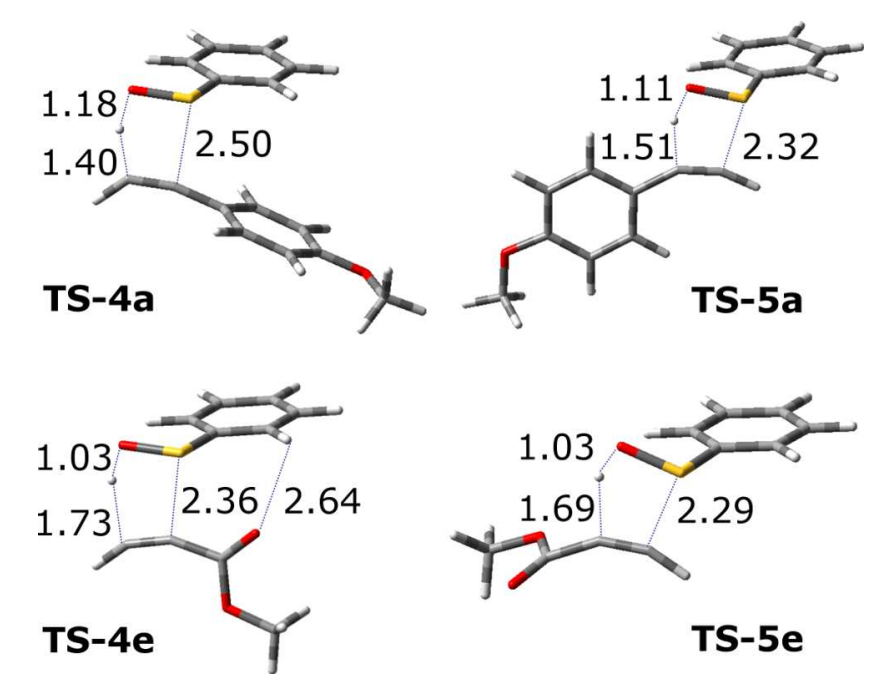

Figure 6. Optimized TSs for the addition of $\mathbf{2}$ to $\mathbf{3 a}$ and 3e. Selected distances are reported in angstrom.

Indeed, the three parameters $d$ (the $\mathrm{H} \cdots \mathrm{O}$ distance), $\theta$ (the $\mathrm{C}-\mathrm{H} \cdots \mathrm{O}$ angle) and $D$ (the distance between the $\mathrm{C}-\mathrm{H}$ carbon and the carbonyl oxygen) measured for TS-4e $\left(d=2.64 \AA, \theta=106.6^{\circ}, D=3.13 \AA\right)$ perfectly fall within the ranges reported in the literature for similar interactions. ${ }^{[25]}$ The energetic contribution of the hydrogen interaction was esteemed by performing a PES scan over the rotation of the $\mathrm{C}-\mathrm{C}=\mathrm{O} \sigma$ bond, followed by a full optimization of the rotamer TS, which resulted $1.3 \mathrm{kcal} / \mathrm{mol}$ less stable than TS-4e at the MPW1B95/6-31+G(d,p),S(3df) level of theory. It is reasonable that such hydrogen interaction stabilizes TS-4e in respect to TS-5e and allows the obtainment of product 4e together with 5e, in contrast with the corresponding result from the HSAB analysis which, being conducted on the isolated reactants, cannot consider any secondary interaction at the TS level.

\section{Conclusions}

DFT calculations with the MPW1B95 functional proved to be adequate for studying the syn-addition of sulfenic acids onto monosubstituted acetylenes. A model based on the local HSAB principle was evaluated for its ability to predict the regiochemical outcome of the studied reactions and qualitative predictions were perfectly in line with experimental results. Quantitative predictions based on the grand potential variation $\Delta \Delta \Omega$ resulted correct for 3a-d,f, but failed for methyl propiolate (3e) where the antiMarkovnikov regioisomer $\mathbf{4 e}$ was predicted as the only product. On the other hand the computational 
analysis of all the stationary points along the reaction PES allowed to accurately compute the differences in activation energies for all the examples herein reported and provided an explanation of the peculiar behavior observed for methyl propiolate. Moreover, the role of the alkyne substituent in affecting the activation barriers, ruling the regiochemical outcome and influencing the reaction mechanism was rationalized and discussed, showing how the ED substituents favor the addition of sulfur on the most substituted carbon while increasing the corresponding TSs asynchronicity by anticipating the protonation step. Contrarily, EW substituents favor the sulfur addition on the least substituted carbon and increase the corresponding TSs asynchronicity by anticipating the nucleophilic attack of the $\mathrm{S}$ atom.

\section{Experimental Section}

Theoretical Calculations. Reactants 2, 3a-f, products 4a-f and 5a-f and the corresponding TSs-4a-f and TSs-5a-f were fully optimized in the gas phase at the MPW1B95/6-31+G(d,p),S(3df) level of theory. ${ }^{[15]}$ Vibrational frequencies were computed at the same level of theory in order to define optimized geometries as minima (no imaginary frequencies) or TSs (a unique imaginary frequency corresponding to the vibrational stretching of the forming/breaking bonds) and to calculate ZPVE and thermochemical corrections to electronic energies (1 atm, 355.0 and $383.6 \mathrm{~K}$, corresponding to the experimental conditions for acetonitrile or toluene at reflux). Single point calculations were performed at the MPW1B95/6-311+G(3df,2p) in the gas phase and in solution (toluene and acetonitrile) using both the PCM and CPCM solvent models. ${ }^{[26,27]}$ Different topological models and set of atomic radii were adopted for the construction of the molecular cavity (the default united atom model UA0 as implemented in Gaussian03, ${ }^{[28]}$ the Pauling, also referred as Merz-Kollman, model, ${ }^{[29]}$ or the Bondi model, $\left.{ }^{[30]}\right)$, but none of the above strategies outperformed gas-phase calculations in terms of reproduction of the experimental outcome. For this reason, all the results herein reported are referred to gas-phase calculations. Competing diradical mechanisms for the sulfoxide syn-eliminations were excluded by Jenks and coworkers through a CASSCF analysis of the TSs, ${ }^{[3 \mathrm{~d}]}$ however the RHF-UHF stability of the wave function was checked for TSs-4a,e and TSs-5a,e, but both RMPW1B95 and UMPW1B95 methods provided the same energy, and no instabilities were observed. IRC analyses were 
performed at the MPW1B95/6-31+G(d,p),S(3df) level starting from TSs-4a,e and TSs-5a,e requesting in each case a step size of 0.1 or $0.05 \mathrm{amu}^{1 / 2}$ bohr. HSAB calculations were performed on reactants 2 , 3a-f optimized at the MPW1B95/6-31+G(d,p),S(3df) level. The anion and cation of 2, 3a-f were treated at the UMPW1B95/6-31+G(d,p),S(3df) level using the geometry of the neutral system. Atomic electron populations were evaluated with the Merz-Kollman charge scheme. ${ }^{[31]}$ Reactivity indexes were computed within the finite difference approximation as $\mu=-(\mathrm{IP}+\mathrm{EA}) / 2$ and $S=1 /(\mathrm{IP}-\mathrm{EA})$, where IP and EA are the vertical ionization potential and the electron affinity, respectively. The condensed form of the local softness was calculated as $s_{k}{ }^{+}=\left[q_{k}(N+1)-q_{k}(N)\right] S$ and $s_{k}{ }^{-}=\left[q_{k}(N)-q_{k}(N-1)\right] S$ for the reactivity towards nucleophiles and electrophiles, respectively, were $q_{k}(N), q_{k}(N+1)$ and $q_{k}(N-1)$ represent the gross electron population of the atom $\mathrm{k}$ in the neutral, anionic and cationic system, respectively. Basis sets using Cartesian $d$ and $f$ functions were always requested and all calculations were performed with the Gaussian03 package. ${ }^{[28]}$

Synthetic part. General. Solvents were purified according to standard procedures. Light petroleum (petrol) used refers to the fraction boiling at $30-50^{\circ} \mathrm{C}$. All reactions were monitored by TLC on commercially available precoated plates (Aldrich silica gel $60 \mathrm{~F} 254$ ) and the products were visualized with vanillin $\left[1 \mathrm{~g}\right.$ dissolved in $\mathrm{CH}_{3} \mathrm{OH}(60 \mathrm{~mL})$ and conc. $\left.\mathrm{H}_{2} \mathrm{SO}_{4}(0.6 \mathrm{~mL})\right]$. Silica gel Aldrich 60 was used for column chromatography. ${ }^{1} \mathrm{H}$ and ${ }^{13} \mathrm{C}$ NMR spectra were recorded on a Varian Mercury 300 spectrometer at 300 and $75 \mathrm{MHz}$ respectively in $\mathrm{CDCl}_{3}$ solutions with $\mathrm{Si}\left(\mathrm{CH}_{3}\right)_{4}$ as internal standard: the attributions are supported by Attached Proton Test (APT) and homodecoupling experiments; proton and carbon nuclei indicated by pertain to the phenylsulfinyl group. Mass spectra were measured by Electron

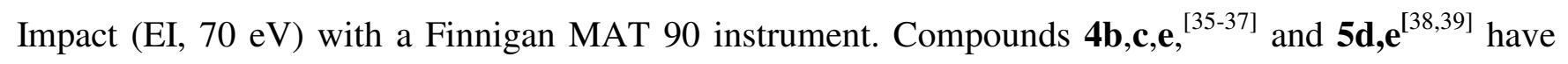
been already described. Additional spectral data are reported for compounds $\mathbf{4 b , c , e}$ and $\mathbf{5 e}$.

\section{General Procedure for the Thermolysis of Sulfoxide 1 in the Presence of Alkynes 3. To a $0.2 \mathrm{M}$} solution of $\mathbf{1}$ in toluene or acetonitrile, the commercial acceptor $\mathbf{3}$ (6 equiv) was added, and the mixture maintained at reflux temperature. When the reaction appeared complete by TLC (disappearance of $\mathbf{1}$, see 
reaction time in Scheme 1), the reaction crude was purified by flash column chromatography on silica gel (EtOAc/petrol from 9:1 to 4:1).

1-(4-Methoxyphenyl)-1-(phenylsulfinyl)-ethene (4a). Pale yellow oil.

TLC $R f$ (EtOAc/petrol 1:1) 0.55; ${ }^{1} \mathrm{H}$ NMR: $\delta$ 7.5-7.3 (m, 5H, H-2"-6"), 7.14 and 6.80 (AA'BB' system, $\left.{ }^{3} J_{\text {ortho }}=9.2 \mathrm{~Hz}, 4 \mathrm{H}, \mathrm{H}-2^{\prime}, 3^{\prime}, 5^{\prime}, 6^{\prime}\right), 6.18$ and $5.84\left(\right.$ two d, $\left.{ }^{2} J_{\text {gem }}=0.5 \mathrm{~Hz}, 2 \mathrm{H}, \mathrm{H}_{2}-2\right), 3.77$ (s, 3H, $\left.\mathrm{CH}_{3}\right) ;{ }^{13} \mathrm{C}$ NMR: $\delta 160.2\left(\mathrm{C}-4\right.$ '), $153.8(\mathrm{C}-1), 142.9\left(\mathrm{C}-1^{\prime \prime}\right), 131.0(\mathrm{C}-4 "), 128.9$ and 125.1 (C2',6',2",3",5",6"), 125.9 (C-1'), 115.2 (C-2), $114.0\left(\mathrm{C}-3^{\prime}, 5^{\prime}\right), 55.2\left(\mathrm{CH}_{3}\right) ; \mathrm{MS}: \mathrm{m} / z(\%) 258(15)$ [M $\left.{ }^{+}\right], 133$ (10), 132 (100), 76 (7). Element. anal. Calcd. (\%) for $\mathrm{C}_{15} \mathrm{H}_{14} \mathrm{O}_{2} \mathrm{~S}$ (258.34): C, 69.74; H, 5.46. Found: C, 69,$68 ; \mathrm{H}, 5.47$.

1-(4-Methylphenyl)-1-(phenylsulfinyl)-ethene (4b). ${ }^{[32]}$ TLC $R f\left(\right.$ EtOAc/petrol 1:1) 0.67; ${ }^{1} \mathrm{H}$ NMR: $\delta$ 7.4-7.3 (m, 5H, H-2"-6"), 7.1 (m, 4H, H-2',3',5',6'), 6.21 and 5.87 (two s, 2H, H2-2), 2.30 (s, 3H, $\mathrm{CH}_{3}$ ); ${ }^{13}$ C NMR: $\delta 154.2$ (C-1), 142.9 (C-1"), 139.1 (C-4'), 131.1 (C-4"), $130.7\left(\mathrm{C}-1^{\prime}\right), 129.3,128.9,127.4$, and 125.2 (C-2',3',5',6',2",3",5",6"), $115.6(\mathrm{C}-2), 21.2\left(\mathrm{CH}_{3}\right) ; \mathrm{MS}: \mathrm{m} / z(\%) 242(2)\left[\mathrm{M}^{+}\right], 126(6), 116(100)$. Element. anal. Calcd. (\%) for $\mathrm{C}_{15} \mathrm{H}_{14} \mathrm{OS}$ (242.34): C, 74.34; H, 5.82. Found: C, 74.37; H, 5.80.

1-Phenyl-1-(phenylsulfinyl)-ethene (4c). ${ }^{[33]}$ TLC $R f\left(\right.$ EtOAc/petrol 1:1) $0.48 ;{ }^{1} \mathrm{H}$ NMR: $\delta$ 7.5-7.3 (m, 10H, H-2'-6',2"-6"), 6.25 and 5.91 (two d, $\left.{ }^{2} J_{\text {gem }}=0.5 \mathrm{~Hz}, 2 \mathrm{H}, \mathrm{H}_{2}-2\right)$; ${ }^{13} \mathrm{C}$ NMR: $\delta 154.3(\mathrm{C}-1), 142.6(\mathrm{C}-$ 1"), 133.6 (C-1'), 131.1 (C-4"), 129.0, 128.9, 128.5, 127.5, and 125.1 (C-2'-6',2",3",5",6"), 116.2 (C-2); Element. anal. Calcd. (\%) for $\mathrm{C}_{14} \mathrm{H}_{12} \mathrm{OS}$ (228.31): C, 73.65; H, 5.30. Found: C, 73.60; H, 5.25.

1-(4-Nitrophenyl)-1-(phenylsulfinyl)-ethene (4d). Light yellow crystals, m.p. 122-124 ${ }^{\circ} \mathrm{C}$. TLC $R f$ (EtOAc/petrol 1:1) 0.50; ${ }^{1} \mathrm{H}$ NMR: $\delta 8.12$ and 7.37 (AA'BB' system, ${ }^{3} J_{\text {ortho }}=8.8 \mathrm{~Hz}, 4 \mathrm{H}, \mathrm{H}-2^{\prime}, 3^{\prime}, 5^{\prime}, 6^{\prime}$ ), 7.4-7.3 (m, 5H, H-2"-6" ), 6.40 and 6.05 (two d, ${ }^{2} J_{\text {gem }}=0.8 \mathrm{~Hz}, 2 \mathrm{H}, \mathrm{H}_{2}-2$ ); ${ }^{13} \mathrm{C}$ NMR: $\delta 153.0(\mathrm{C}-1$ ), 148.0 (C-4'), 141.8 (C-1"), 140.0 (C-1'), 131.7 (C-4"), 129.2, 128.5, 125.1, and 123.7 (C-

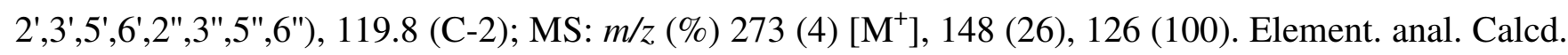
(\%) for $\mathrm{C}_{14} \mathrm{H}_{11} \mathrm{NO}_{3} \mathrm{~S}$ (273.31): C, 61.52; H, 4.06. Found: C, 61.50; H, 4.10.

Methyl 2-(phenylsulfinyl)-2-propenoate (4e). ${ }^{[34]}$ TLC $R f\left(\right.$ EtOAc/petrol 1:1) $0.55 ;{ }^{1} \mathrm{H}$ NMR: $\delta$ 7.7$7.5(\mathrm{~m}, 5 \mathrm{H}, \mathrm{H}-2 "-6 ")$ ), 6.87 and 6.71 (two d, $\left.{ }^{2} J_{\text {gem }}=0.5 \mathrm{~Hz}, 2 \mathrm{H}, \mathrm{H}_{2}-3\right), 3.72\left(\mathrm{~s}, 3 \mathrm{H}, \mathrm{CH}_{3}\right) ;{ }^{13} \mathrm{C}$ NMR: $\delta$ 
162.2 (C-1), 147.3 (C-2), 143.0 (C-1"), 131.7 (C-4"), 129.2 and 125.9 (C-2",3",5",6"), 128.5 (C-3), 52.3 $\left(\mathrm{CH}_{3}\right)$; MS: m/z (\%) $210(100)\left[\mathrm{M}^{+}\right], 179$ (14), 126 (31), 125 (99), 77(62). Element. anal. Calcd. (\%) for $\mathrm{C}_{10} \mathrm{H}_{10} \mathrm{O}_{3} \mathrm{~S}$ (210.25): C, 57.13; H, 4.79. Found: C, 57.10; H, 4.77.

(E)-1-(4-Nitrophenyl)-2-(phenylsulfinyl)-ethene $(\mathbf{5 d}) .^{[35]}$ It was identified by comparison with published characterization data.

Methyl (E)-3-(phenylsulfinyl)-2-propenoate (5e). ${ }^{[36]}$ TLC $R f\left(\right.$ EtOAc/petrol 1:1) $0.52 ;{ }^{1} \mathrm{H}$ NMR: $\delta$ 7.6-7.5 (m, 5H, H-2"-6" ), $7.50\left(\mathrm{AB} \mathrm{d}, J_{2,3}=14.8 \mathrm{~Hz}, 1 \mathrm{H}, \mathrm{H}-3\right), 6.75(\mathrm{AB} \mathrm{d}, 1 \mathrm{H}, \mathrm{H}-2), 3.78(\mathrm{~s}, 3 \mathrm{H}$, $\left.\mathrm{CH}_{3}\right) ;{ }^{13} \mathrm{C}$ NMR: $\delta 164.3$ (C-1), 151.3 (C-3), 141.4 (C-1"), 131.8 (C-4"), 129.7 and 124.7 (C-2",3",5",6"), $123.6(\mathrm{C}-2), 52.3\left(\mathrm{CH}_{3}\right)$; MS: m/z (\%) $210(20)\left[\mathrm{M}^{+}\right], 162$ (100), 131 (64), 109 (46), 77 (31). Element. anal. Calcd. (\%) for $\mathrm{C}_{10} \mathrm{H}_{10} \mathrm{O}_{3} \mathrm{~S}$ (210.25): C, 57.13; H, 4.79. Found: C, 57.15; H, 4.80.

(E)-1-(Trimethylsilyl)-2-(phenylsulfinyl)-ethene (5f). TLC $R f\left(\right.$ EtOAc/petrol 1:1) $0.70 ;{ }^{1} \mathrm{H}$ NMR: $\delta$ 7.6-7.5 (m, 5H, H-2”-6”), $6.96\left(\mathrm{AB} \mathrm{d}, J_{1,2}=17.5 \mathrm{~Hz}, 1 \mathrm{H}, \mathrm{H}-2\right), 6.63(\mathrm{AB} \mathrm{d}, 1 \mathrm{H}, \mathrm{H}-1), 0.13(\mathrm{~s}, 9 \mathrm{H}$, $\left.\mathrm{CH}_{3}\right) ;{ }^{13} \mathrm{C}$ NMR: $\delta 146.7$ (C-2), 143.4 (C-1"), 136.3 (C-1), 131.0 (C-4"), 129.4 and 124.7 (C-2",3",5",6"), - $1.7\left(\mathrm{CH}_{3}\right)$; Element. anal. Calcd. (\%) for $\mathrm{C}_{11} \mathrm{H}_{16} \mathrm{OSSi}$ (224.39): C, 58.88; H, 7.19. Found: C, 58.91; H, 7.17.

Acknowledgment. We thank the "Ministero dell'Istruzione, Università e Ricerca" (MIUR) for financial support and the "Centro Interuniversitario Lombardo per l'Elaborazione Automatica” (CILEA) for computational facilities.

Supporting Information Available: Further computational details, extended tables, Cartesian coordinates, and energies of the mentioned stationary points.

\section{References}

[1] L. A. G. M. Van Den Broek, L. P. C. Delbressine, H. C. J. Ottenheijm, in The Chemistry of Sulphenic Acids and their Derivatives, (Ed. S. Patai), John Wiley \& Sons, Chichester 1990, pp 701-721. 
[2] (a) M. C. Aversa, A. Barattucci, P. Bonaccorsi, P. Giannetto, D. N. Jones, J. Org. Chem. 1997, 62, 4376-4384. (b) M. C. Aversa, A. Barattucci, P. Bonaccorsi, P. Giannetto, M. Policicchio, J. Org. Chem. 2001, 66, 4845-4851. (c) V. Aucagne, M. C. Aversa, A. Barattucci, P. Bonaccorsi, P. Giannetto, P. Rollin, A. Tatibouët, J. Org. Chem. 2002, 67, 6925-6930. (d) M. C. Aversa, A. Barattucci, P. Bonaccorsi, P. Giannetto, J. Org. Chem. 2005, 70, 1986-1992. (e) M. C. Aversa, A. Barattucci, M. C. Bilardo, P. Bonaccorsi, P. Giannetto, P. Rollin, A. Tatibouët, J. Org. Chem. 2005, 70, 7389-7396.

[3] (a) H. Beckers, S. Esser, T. Metzroth, M. Behnke, H. Willner, J. Gauss, J. Hahn, Chem. - Eur. J., 2006, 12, 832-844. (b) G. Winnewisser, F. Lewen, S. Thorwirth, M. Behnke, J. Hahn, J. Gauss, E. Herbst, Chem. - Eur. J. 2003, 9, 5501-5510. (c) S. Nakamura, S. Kusuda, K. Kawamura, T. Toru, J. Org. Chem. 2002, 67, 640-647. (d) J. W. Cubbage, Y. Guo, R. D. McCulla, W. S. Jenks, J. Org. Chem. 2001, 66, 8722-8736. (e) S. Lacombe, M. Loudet, E. Banchereau, M. Simon, G. Pfister-Guillouzo, J. Am. Chem. Soc. 1996, 118, 1131-1138.

[4] B. S. Jursic, THEOCHEM 1997, 389, 257-263.

[5] B. Balta, G. Monard, M. F. Ruiz-López, M. Antoine, A. Gand, S. Boschi-Muller, G. Branlant, J. Phys. Chem. A 2006, 110, 7628-7636.

[6] J. Poater, M. Solà, M. Duran, X. Fradera, J. Phys. Chem. A 2001, 105, 2052-2063.

[7] A. H. Otto, R. Steudel, Eur. J. Inorg. Chem. 2000, 617-624.

[8] D. R. Hogg, in The Chemistry of Sulphenic Acids and their Derivatives, (Ed. S. Patai), John Wiley \& Sons, Chichester, 1990, pp 388-395.

[9] (a) R. G. Pearson, J. Am. Chem. Soc. 1963, 85, 3533-3539. (b) P. K. Chattaraj, H. Lee, R. G. Parr, J. Am. Chem. Soc. 1991, 113, 1855-1856. (c) A. Cedillo, P. K. Chattaraj, R. G. Parr, Int. J. Quantum Chem. 2000, 77, 403-407. 
[10] H. Adams, J. C. Anderson, R. Bell, D. N. Jones, M. R. Peel, N. C. O. Tomkinson, J. Chem. Soc., Perkin Trans. 1 1998, 3967-3974.

[11] (a) C. Lee, W. Yang, R. G. Parr, Phys. Rev. B: Condens. Matter Mater. Phys. 1988, 37, 785-789. (b) A. D. Becke, J. Chem. Phys. 1993, 98, 5648-5652.

[12] (a) V. Barone, L. Orlandini, C. Adamo, Chem. Phys. Lett. 1994, 231, 295-300. (b) V. Barone, L. Orlandini, C. Adamo, Int. J. Quantum Chem. 1995, 56, 697-705. (c) B. G. Johnson, C. A. Gonzales, P. M. W. Gill, J. A. Pople, Chem. Phys. Lett. 1994, 221, 100-108.

[13] R. G. Parr, W. Yang, in Density Functional Theory of Atoms and Molecules, Oxford University Press, Oxford, 1989.

[14] (a) A. Dybala-Defratyka, P. Paneth, J. Pu, D. G. Truhlar, J. Phys. Chem. A 2004, 108, 2475-2486. (b) Y. Zhao, D. G. Truhlar, J. Phys. Chem. A 2004, 108, 6908-6918. (c) A. D. Boese, J. M. L. Martin, J. Chem. Phys. 2004, 121, 3405-3416. (d) Y. Zhao, J. Pu, B. J. Lynch, D. G. Truhlar, Phys. Chem. Chem. Phys. 2004, 6, 673-676. (e) Y. Zhao, D. G. Truhlar, Phys. Chem. Chem. Phys. 2005, 7, 2701-2705. (f) J. Pu, D. G. Truhlar, J. Phys. Chem. A 2005, 109, 773-778. (g) B. J. Lynch, Y. Zhao, D. G. Truhlar, J. Phys. Chem. A 2005, 109, 1643-1649. (h) Y. Zhao, N. González-García, D. G. Truhlar, J. Phys. Chem. A $\mathbf{2 0 0 5}, 109,2012-2018$.

[15] (a) E. Juaristi, R. Notario, M. V. Roux, Chem. Soc. Rev. 2005, 34, 347-354. (b) M. V. Roux, M. Temprado, P. Jiménez, J. Z. Dávalos, R. Notario, G. Martín-Valcárel, L. Garrido, R. Guzmán-Mejía, E. Juaristi, J. Org. Chem. 2004, 69, 5454-5459.

[16] (a) H. Chermette, J. Comput. Chem. 1999, 20, 129-154. (b) P. Geerlings, F. De Proft, W. Langenaeker, Chem. Rev. 2003, 103, 1793-1874. (c) P. W. Ayers, J. S. M. Anderson, L. J. Bartolotti, Int. J. Quantum Chem. 2005, 101, 520-534.

[17] R. G. Parr, W. Yang, J. Am. Chem. Soc. 1984, 106, 4049-4050. 
[18] W. Yang, W. J. Mortier, J. Am. Chem. Soc. 1986, 108, 5708-5711.

[19] J. L. Gázquez, F. Méndez, J. Phys. Chem. 1994, 98, 4591-4593.

[20] (a) D. Sengupta, A. K. Chandra, M. T. Nguyen, J. Org. Chem. 1997, 62, 6404-6406. (b) S. Damoun, G. Van de Woude, F. Méndez, P. Geerlings, J. Phys. Chem. A 1997, 101, 886-893.

[21] A. Ponti, J. Phys. Chem. A 2000, 104, 8843-8846.

[22] (a) A. Ponti, G. Molteni, J. Org. Chem. 2001, 66, 5252-5255. (b) G. Molteni, A. Ponti, Tetrahedron 2003, 59, 5225-5229. (c) G. Molteni, A. Ponti, Chem. - Eur. J. 2003, 9, 2770-2774. (d) A. Ponti, G. Molteni, Chem. - Eur. J. 2006, 12, 1156-1161. (e) G. Molteni, A. Ponti, ARKIVOC (Gainesville, FL, U. S.) 2006, 49-56.

[23] (a) J. P. Foster, F. Weinhold, J. Am. Chem. Soc. 1980, 102, 7211-7228. (b) A. E. Reed, F. Weinhold, J. Chem. Phys. 1983, 78, 4066-4073. (c) A. E. Reed, F. Weinhold, J. Chem. Phys. 1985, 83, 1736-1740. (d) A. E. Reed, L. A. Curtiss, F. Weinhold, Chem. Rev. 1988, 88, 899-926.

[24] J. A. Dobado, H. Martínez-García, J. Molina Molina, M. R. Sundberg, J. Am. Chem. Soc. 1999, $121,3156-3164$

[25] G. R. Desiraju, Chem. Commun. (Cambridge, U. K.) 2005, 2995-3001.

[26] M. Cossi, G. Scalmani, N. Rega, V. Barone, J. Chem. Phys. 2002, 117, 43-54.

[27] M. Cossi, N. Rega, G. Scalmani, V. Barone, J. Comput. Chem. 2003, 24, 669-681.

[28] Gaussian 03, Revision C.02, M. J. Frisch, G. W. Trucks, H. B. Schlegel, G. E. Scuseria, M. A. Robb, J. R. Cheeseman, J. A. Montgomery, Jr., T. Vreven, K. N. Kudin, J. C. Burant, J. M. Millam, S. S. Iyengar, J. Tomasi, V. Barone, B. Mennucci, M. Cossi, G. Scalmani, N. Rega, G. A. Petersson, H. Nakatsuji, M. Hada, M. Ehara, K. Toyota, R. Fukuda, J. Hasegawa, M. Ishida, T. Nakajima, Y. Honda, O. Kitao, H. Nakai, M. Klene, X. Li, J. E. Knox, H. P. Hratchian, J. B. Cross, V. Bakken, C. Adamo, J. 
Jaramillo, R. Gomperts, R. E. Stratmann, O. Yazyev, A. J. Austin, R. Cammi, C. Pomelli, J. W. Ochterski, P. Y. Ayala, K. Morokuma, G. A. Voth, P. Salvador, J. J. Dannenberg, V. G. Zakrzewski, S. Dapprich, A. D. Daniels, M. C. Strain, O. Farkas, D. K. Malick, A. D. Rabuck, K. Raghavachari, J. B. Foresman, J. V. Ortiz, Q. Cui, A. G. Baboul, S. Clifford, J. Cioslowski, B. B. Stefanov, G. Liu, A. Liashenko, P. Piskorz, I. Komaromi, R. L. Martin, D. J. Fox, T. Keith, M. A. Al-Laham, C. Y. Peng, A. Nanayakkara, M. Challacombe, P. M. W. Gill, B. Johnson, W. Chen, M. W. Wong, C. Gonzalez, and J. A. Pople, Gaussian, Inc., Wallingford CT, 2004.

[29] Handbook of Chemistry and Physics, (Ed. R. C. Weast), CRC Press, Cleveland, OH, 1981.

[30] A. Bondi, J. Phys. Chem. 1964, 68, 441-451.

[31] B. H. Besler, K. M. Jr. Merz, P. A. Kollman, J. Comput. Chem. 1990, 11, 431-439.

[32] X. Creary, M. E. Mehrsheikh-Mohammadi, M. D. Eggers, J. Am. Chem. Soc. 1987, 109, $2435-$ 2442.

[33] M. Kawakita, K. Yokota, H. Akamatsu, S. Irisawa, O. Morikawa, H. Konishi, K. Kobayashi, J. Org. Chem. 1997, 62, 8015-8017.

[34] F. Leyendecker, M. T. Comte, Tetrahedron 1986, 42, 1413-1421.

[35] J. H. van Steenis, J. J. G. S. van Es, A. van der Gen, Eur J. Org. Chem. 2000, 2787-2793.

[36] F. A. Davis, A. J. Friedman, U. K. Nadir, J. Am. Chem. Soc. 1978, 100, 2844-2852. 
Table 1. Performance of different density functionals in respect to experiments or MP2 calculations.

\begin{tabular}{lllll}
\hline Method $^{a}$ & $\Delta H^{*} \mathbf{a}$ & $\Delta H^{*} \mathbf{b}$ & $\mathrm{r}^{2 b}$ & Std error $^{b}$ \\
\hline B3LYP & 29.3 & 41.0 & 0.99997 & 0.25 \\
MPW1B95 & 32.1 & 43.7 & 0.99999 & 0.17 \\
MPWB1K & 35.5 & 46.6 & 0.99998 & 0.22 \\
TPSS1KCIS & 29.0 & 41.6 & 0.99998 & 0.19 \\
MPW3LYP & 29.3 & 41.0 & 0.99998 & 0.23 \\
MPWKCIS1K & 36.1 & 47.2 & 0.99996 & 0.29 \\
Exp. $^{3 \mathrm{~d}}$ & 33.0 & 42.0 & & \\
\hline
\end{tabular}

${ }^{\mathrm{a}}$ DFT calculations performed with the $6-31+\mathrm{G}(\mathrm{d}, \mathrm{p}), \mathrm{S}(3 \mathrm{df})$ basis set. ${ }^{\mathrm{b}}$ Regression analysis between DFT and MP2/6-311+(3df,2p) geometrical parameters reported in reference $3 \mathrm{~d}$. A total of 18 bond distances and 2 bond angles were compared.

Table 2. Local softness computed for atoms involved in the addition of $\mathbf{2}$ to $\mathbf{3 a - f},{ }^{\mathrm{a}}$ HSAB fulfilment degrees $\Delta_{4}$ and $\Delta_{5}$, chemical potential differences $\Delta \mu_{2-3}(\mathrm{eV})$, and differences in grand potential variation $\Delta \Delta \Omega_{R 1-R 2}(\mathrm{~kJ} / \mathrm{mol}) .^{\mathrm{b}}$

\begin{tabular}{llllllllll}
\hline $\mathrm{RC} \equiv \mathrm{CH}$ & $\mathrm{R}$ & $s^{+}{ }_{\mathrm{C}-\mathrm{H}}$ & $s^{+}{ }_{\mathrm{C}-\mathrm{R}}$ & $s_{\mathrm{C}-\mathrm{H}}$ & $s_{\mathrm{C}-\mathrm{R}}^{-}$ & $\Delta_{4}{ }^{c}$ & $\Delta_{5}{ }^{c}$ & $\Delta \mu_{2-3}$ & $\Delta \Delta \Omega_{4-5}$ \\
\hline 3a & $p-\mathrm{CH}_{3} \mathrm{OC}_{6} \mathrm{H}_{4}$ & 0.83 & -0.08 & 0.83 & -0.15 & 3.43 & 4.44 & -0.05 & $-3.9 \times 10^{-2}$ \\
3b & $p-\mathrm{CH}_{3} \mathrm{C}_{6} \mathrm{H}_{4}$ & 0.73 & -0.02 & 0.89 & -0.03 & 3.13 & 4.11 & 0.26 & $-4.8 \times 10^{-4}$ \\
3c & $\mathrm{Ph}$ & 0.60 & 0.21 & 0.79 & 0.23 & 2.71 & 3.40 & 0.45 & $-1.6 \times 10^{-2}$ \\
3d & $p-\mathrm{NO}_{2} \mathrm{C}_{6} \mathrm{H}_{4}$ & 0.55 & -0.11 & 0.99 & 0.18 & 3.22 & 3.65 & 1.71 & $2.0 \times 10^{-1}$ \\
3e & $\mathrm{COOCH}_{3}$ & 1.19 & -0.40 & 0.53 & 0.62 & 5.23 & 1.61 & 1.40 & $4.2 \times 10^{0}$ \\
3f & $\mathrm{TMS}$ & 0.34 & -0.21 & 0.75 & 0.56 & 4.02 & 2.94 & 0.90 & $5.9 \times 10^{-1}$
\end{tabular}

\footnotetext{
${ }^{\mathrm{a}}$ The following values were computed for benzenesulfenic acid $(2): \mathrm{s}^{+}(\mathrm{S})=1.94 ; \mathrm{s}^{-}(\mathrm{S})=1.46 ; \mathrm{s}^{+}(\mathrm{H})=$ 1.86; $\mathrm{s}^{-}(\mathrm{H})=0.06{ }^{\mathrm{b}}$ For the calculation of the HSAB fulfilment degrees $\Delta$ and grand potential variation $\Delta \Delta \Omega$ the acidic hydrogen was considered the electrophile and sulfur the nucleophile. ${ }^{\mathrm{c}} \Delta_{4}=\left(\mathrm{s}^{+}{ }_{\mathrm{H}}-\mathrm{s}_{\mathrm{C}-\mathrm{H}}^{-}\right)^{2}$ $+\left(\mathrm{s}_{\mathrm{S}}^{-}-\mathrm{s}_{\mathrm{C}-\mathrm{R}}^{+}\right)^{2} ; \Delta_{5}=\left(\mathrm{s}_{\mathrm{H}}^{+}-\mathrm{s}_{\mathrm{C}-\mathrm{R}}^{-}\right)^{2}+\left(\mathrm{s}_{\mathrm{S}}^{-}-\mathrm{S}_{\mathrm{C}-\mathrm{H}}^{+}\right)^{2}$
} 
Table 3. Activation and reaction free energies ( $\mathrm{kcal} / \mathrm{mol})$ for the addition of $\mathbf{2}$ to $\mathbf{3 a - f}$, and activation and reaction free energy differences $(\mathrm{kcal} / \mathrm{mol})$ between regioisomers $\mathbf{4}$ and $\mathbf{5}^{\text {a }}$

\begin{tabular}{|c|c|c|c|c|c|c|c|}
\hline $\mathrm{RC} \equiv \mathrm{CH}$ & $\mathrm{R}$ & $\Delta G_{4}^{\ddagger}$ & $\Delta G^{\ddagger}$ & $\Delta G_{4}$ & $\Delta G_{5}$ & $\Delta \Delta G^{\ddagger} 4-5$ & $\Delta \Delta G_{4-5}$ \\
\hline $\mathbf{3 a}$ & $p-\mathrm{CH}_{3} \mathrm{OC}_{6} \mathrm{H}_{4}$ & 24.6 & 27.1 & -10.0 & -11.8 & 2.5 & -1.8 \\
\hline $3 b$ & $p-\mathrm{CH}_{3} \mathrm{C}_{6} \mathrm{H}_{4}$ & 25.0 & 27.9 & -10.0 & -12.5 & 2.9 & -2.5 \\
\hline $3 c$ & $\mathrm{Ph}$ & 25.0 & 27.9 & -9.8 & -12.5 & 2.9 & -2.7 \\
\hline $3 d$ & $p-\mathrm{NO}_{2} \mathrm{C}_{6} \mathrm{H}_{4}$ & 25.2 & 26.4 & -9.8 & -12.2 & 1.4 & -2.4 \\
\hline $3 \mathbf{e}$ & $\mathrm{COOCH}_{3}$ & 22.9 & 22.0 & -15.9 & -18.2 & -0.9 & -2.3 \\
\hline $3 f$ & TMS & 29.1 & 26.6 & -4.3 & -5.5 & -2.5 & -1.3 \\
\hline
\end{tabular}

\begin{abstract}
${ }^{\mathrm{a}}$ Calculated as the sum of MPW1B95/6-311+G(3df,2p) energy and the thermal correction to Gibbs free energy obtained from thermochemical calculations $(383.6 \mathrm{~K}, 1 \mathrm{~atm}$, in order to simulate the reaction experimental conditions for toluene) at the MPW1B95/6-31+G(d,p),S(3df) level. Activation barriers are calculated as the energy difference between TSs and the sum of the energies of isolated reactants 1 and 3a-f, while reaction energies correspond to the energy differences between products and the sum of the isolated reactants energies.
\end{abstract}

Table 4. Selected Wiberg bond order indexes. ${ }^{\text {a }}$ BOI differences between the forming bonds in TSs are reported in parenthesis.

\begin{tabular}{llllll}
\hline Species & C-H & C-S & C-C & S-O & O-H \\
\hline TS-4a & 0.37 & $0.29(0.08)$ & 2.35 & 1.04 & 0.39 \\
TS-5a & 0.27 & $0.41(0.14)$ & 2.31 & 1.02 & 0.46 \\
$\mathbf{4 a}$ & 0.90 & 0.88 & 1.89 & 1.24 & \\
$\mathbf{5 a}$ & 0.88 & 0.93 & 1.82 & 1.25 & \\
TS-4b & 0.35 & $0.31(0.04)$ & 2.36 & 1.03 & 0.41 \\
TS-5b & 0.27 & $0.41(0.14)$ & 2.32 & 1.01 & 0.45 \\
$\mathbf{4 b}$ & 0.90 & 0.88 & 1.89 & 1.24 & \\
$\mathbf{5 b}$ & 0.88 & 0.93 & 1.82 & 1.25 & \\
TS-4c & 0.35 & $0.30(0.05)$ & 2.36 & 1.03 & 0.40 \\
\hline
\end{tabular}




\begin{tabular}{llllll}
\hline TS-5c & 0.26 & $0.42(0.16)$ & 2.33 & 1.01 & 0.46 \\
4c & 0.89 & 0.88 & 1.89 & 1.25 & \\
5c & 0.88 & 0.93 & 1.83 & 1.25 & \\
TS-4d & 0.34 & $0.31(0.03)$ & 2.36 & 1.04 & 0.41 \\
TS-5d & 0.18 & $0.48(0.30)$ & 2.33 & 0.98 & 0.52 \\
4d & 0.89 & 0.87 & 1.89 & 1.25 & \\
5d & 0.87 & 0.93 & 1.83 & 1.25 & \\
TS-4e & 0.15 & $0.33(0.18)$ & 2.47 & 0.95 & 0.57 \\
TS-5e & 0.15 & $0.43(0.28)$ & 2.40 & 0.97 & 0.55 \\
4e & 0.89 & 0.88 & 1.86 & 1.24 & \\
$\mathbf{5 e}$ & 0.87 & 0.93 & 1.85 & 1.26 & \\
TS-4f & 0.36 & $0.38(0.02)$ & 2.39 & 1.04 & 0.40 \\
TS-5f & 0.30 & $0.45(0.15)$ & 2.38 & 1.01 & 0.43 \\
4f & 0.89 & 0.91 & 1.93 & 1.25 & \\
$\mathbf{5 f}$ & 0.87 & 0.91 & 1.94 & 1.25 & \\
\hline and O-H BOIs for $\mathbf{2}$ are 0.89 and 0.71, respectively. & \\
\hline
\end{tabular}


TOC (graphical abstract)

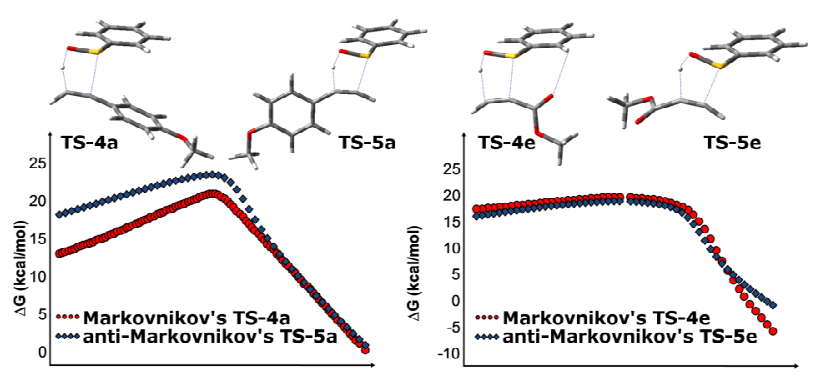

The reaction of benzenesulfenic acid with monosubstituted alkynes was experimentally and theoretically investigated. A model based on the HSAB principle was evaluated for its ability to qualitatively and quantitatively predict the regioselectivity. Kinetics and thermodynamics of the reaction were studied through the computational analysis of the reaction path. 


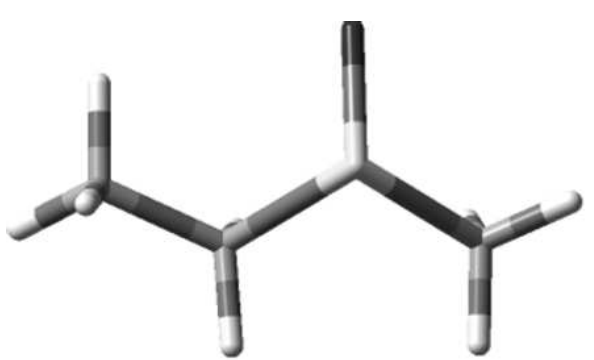

a

C-S: $1.81(1.80)$

C-H: 1.09 (1.09)

S-O: $1.48(1.49)$

C-C: $1.52(1.52)$

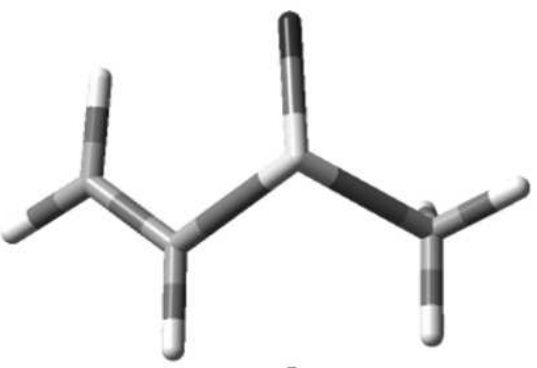

b

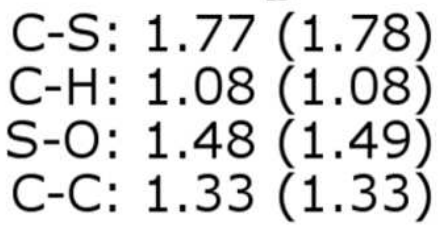

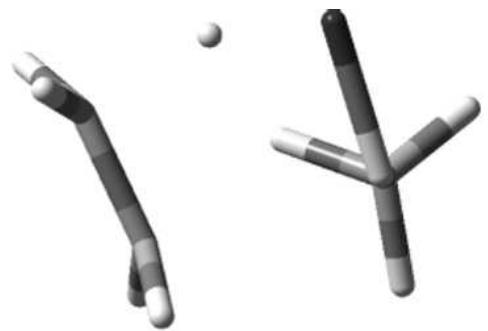

TS-a

C-S: $2.34(2.33)$

$\mathrm{C}-\mathrm{H}: 1.41(1.42)$

S-O: $1.55(1.57)$

C-C: 1.40 (1.40)

$\mathrm{O}-\mathrm{H}: 1.19(1.17)$

C-H-O: 154.2 (153.4)

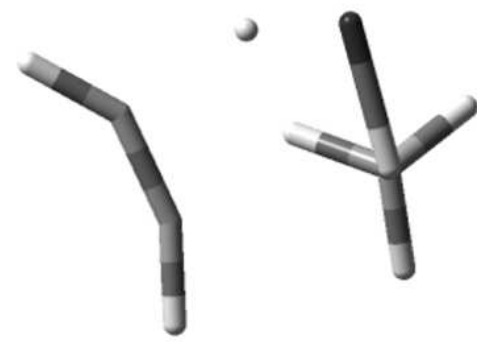

TS-b

C-S: $2.34(2.33)$

$\mathrm{C}-\mathrm{H}: 1.56(1.48)$

S-O: $1.57(1.57)$

C-C: $1.25(1.25)$

$\mathrm{O}-\mathrm{H}: 1.08(1.13)$

C-H-O: 149.9 (150.1)

Figure 1. MPW1B95/6-31+G(d,p),S(3df) optimized reactants and TSs for the thermolysys of sulfoxides $a$ and $b$, with MP2/6-311+G(3df,2p) values in parenthesis.3d Distances are reported in angstroms, angles in degrees. $83 \times 97 \mathrm{~mm}(300 \times 300$ DPI $)$ 

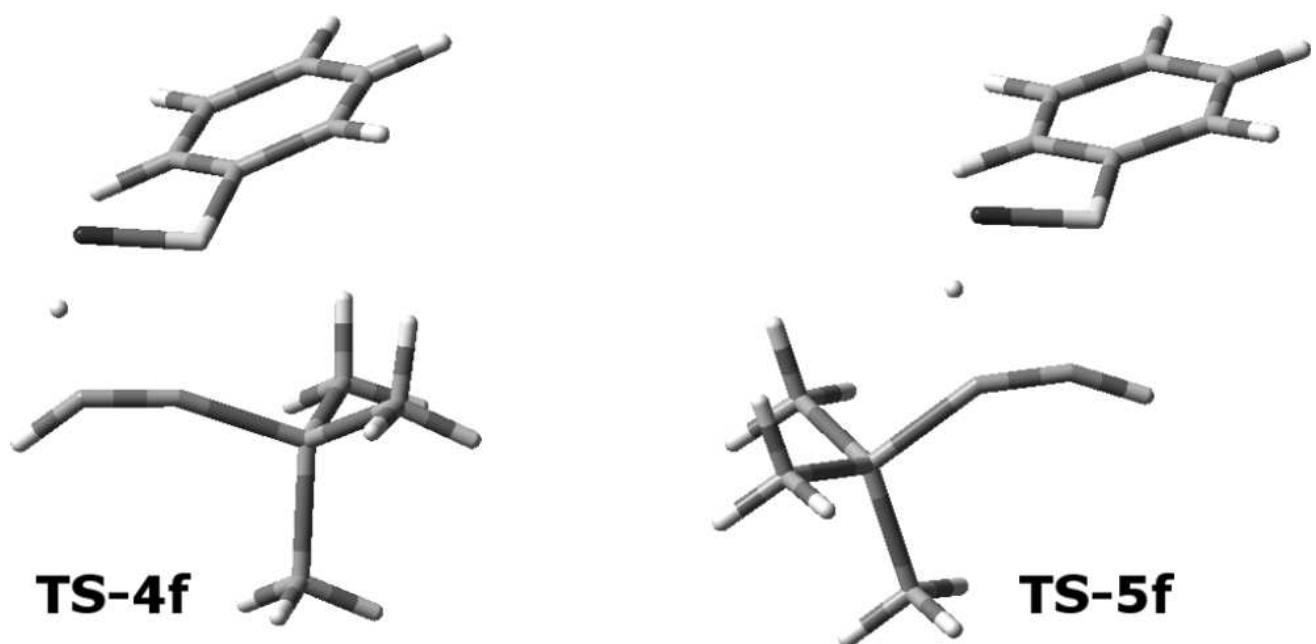

Figure 2. Optimized TS-4f and TS-5f. $83 \times 40 \mathrm{~mm}(300 \times 300 \mathrm{DPI})$ 

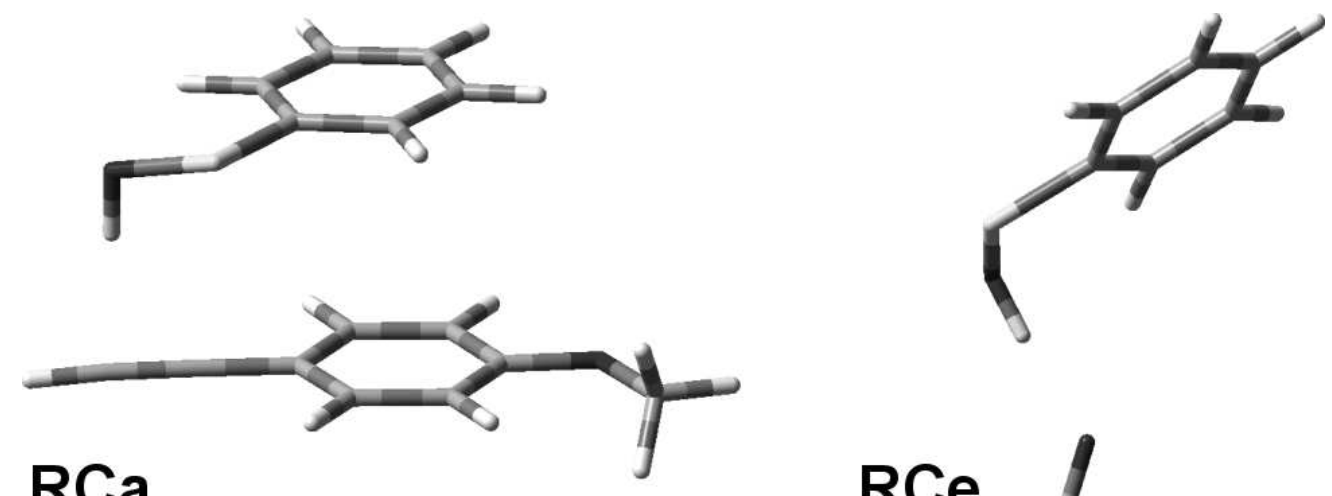

$\mathrm{RCa}$
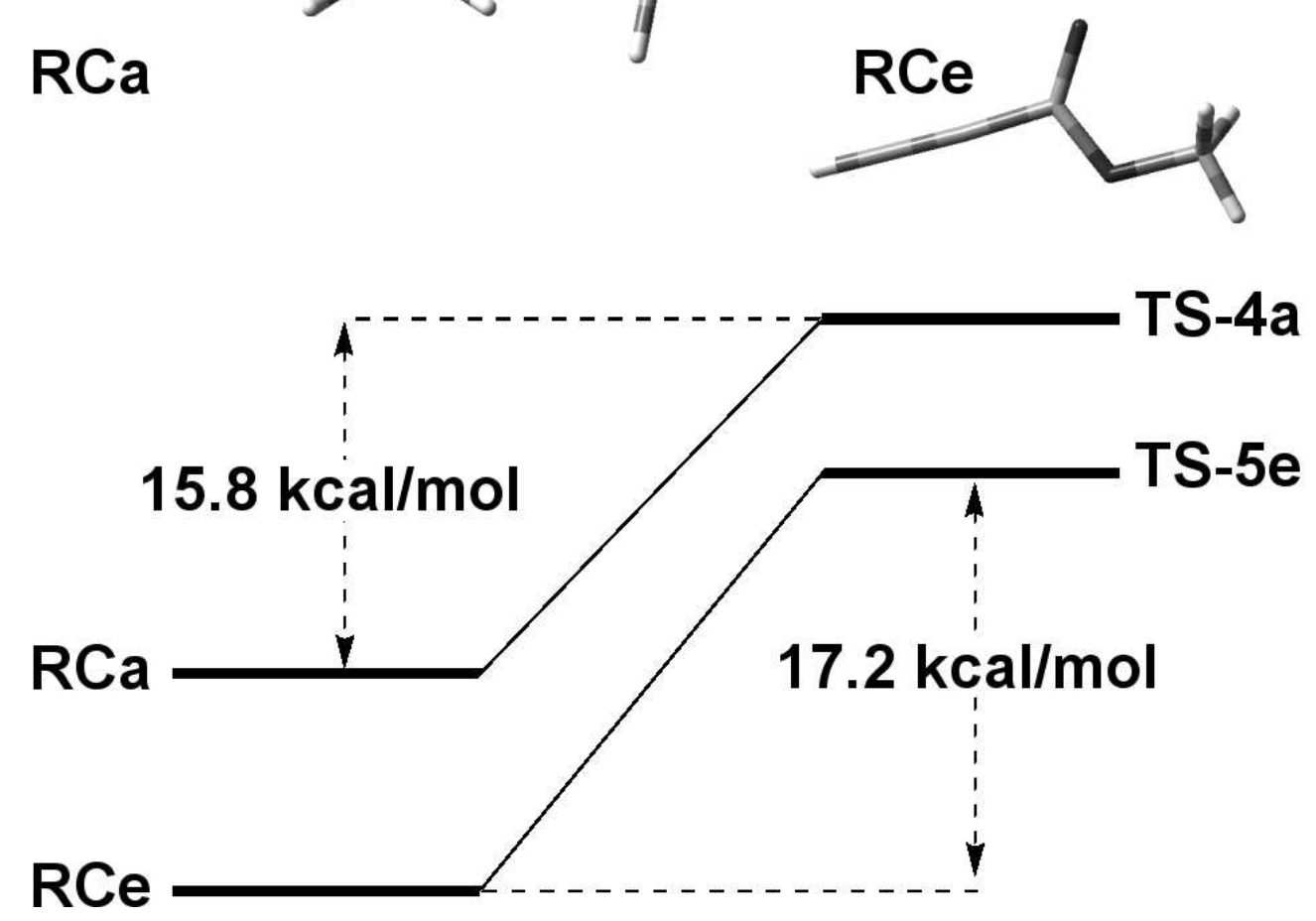

Figure 3. Reactant complexes obtained between 2 and $3 a(R C a)$ or $3 e(R C e)$ and free energy barriers between RCs and corresponding TSs $81 \times 82 \mathrm{~mm}(300 \times 300 \mathrm{DPI})$ 


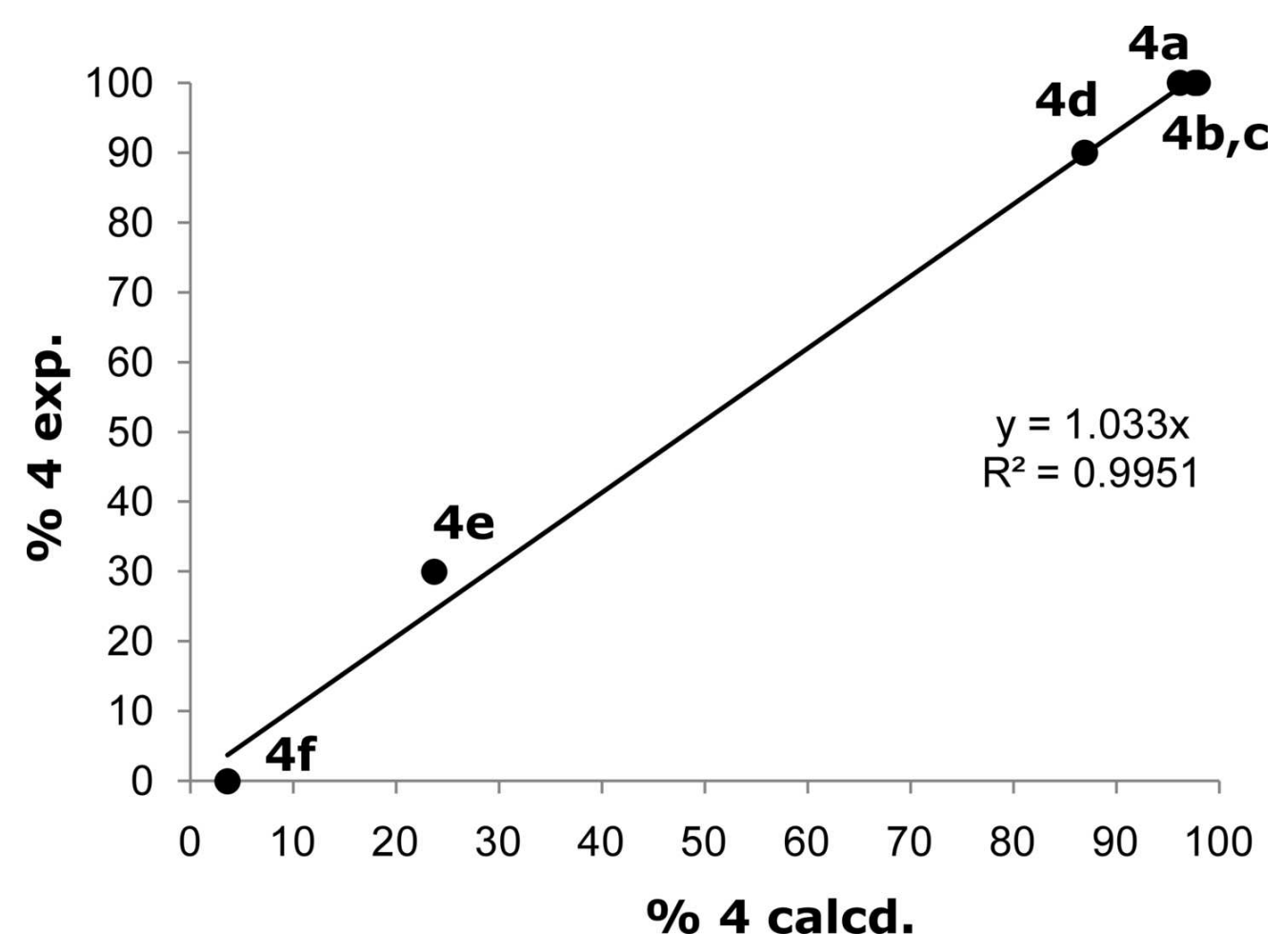

Figure 4. Predicted vs experimental percentage of regioisomers 4. $61 \times 45 \mathrm{~mm}(600 \times 600 \mathrm{DPI})$ 


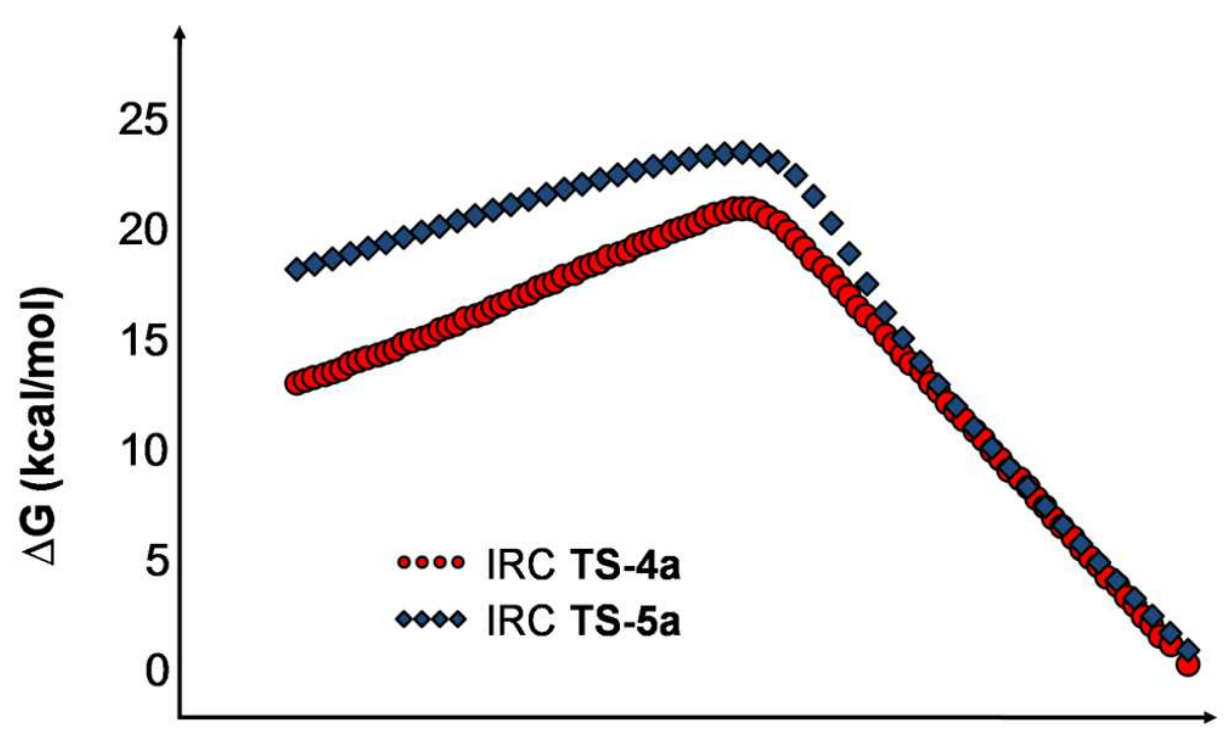

\section{Reaction Coordinates}

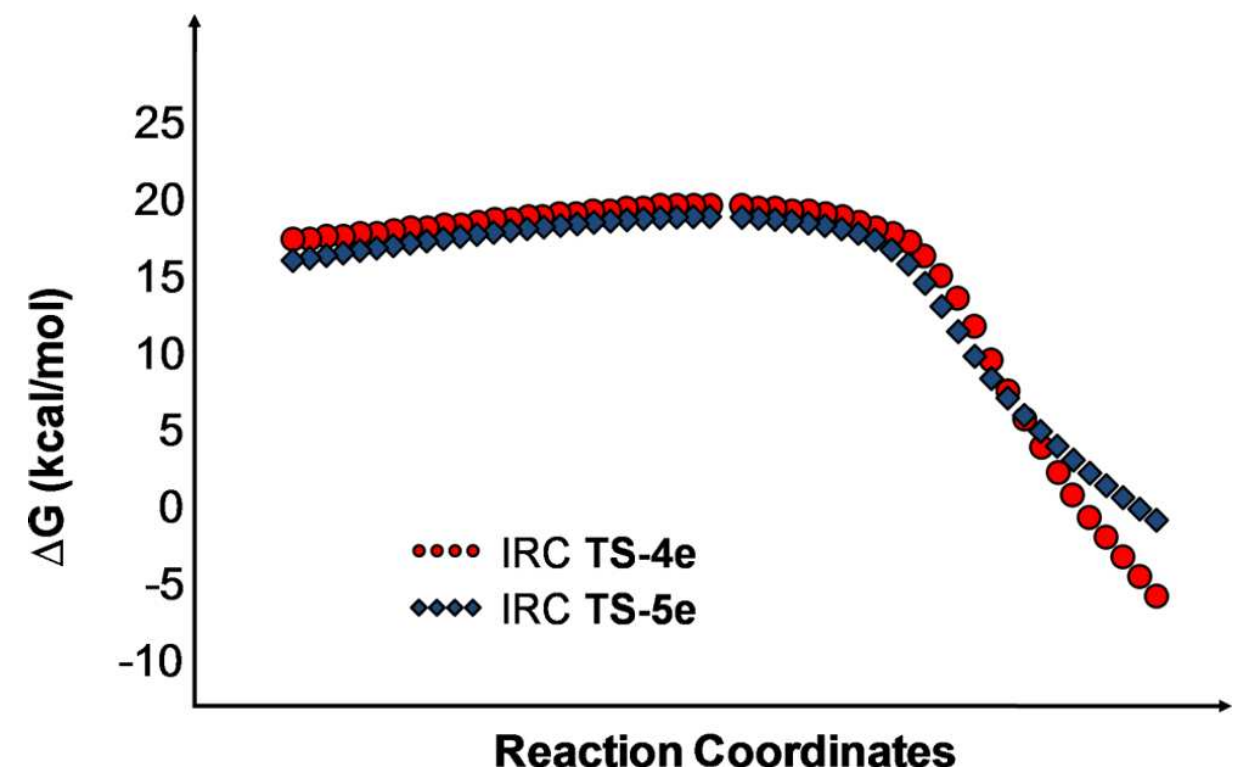

Figure 5. IRC calculations for the reactions of 2 with $3 a$ and $3 e$ at MPW1B95/6-31+G(d,p),S(3df). Relative energies are referred to the energy of the isolated reactants. $83 \times 108 \mathrm{~mm}(300 \times 300$ DPI $)$ 

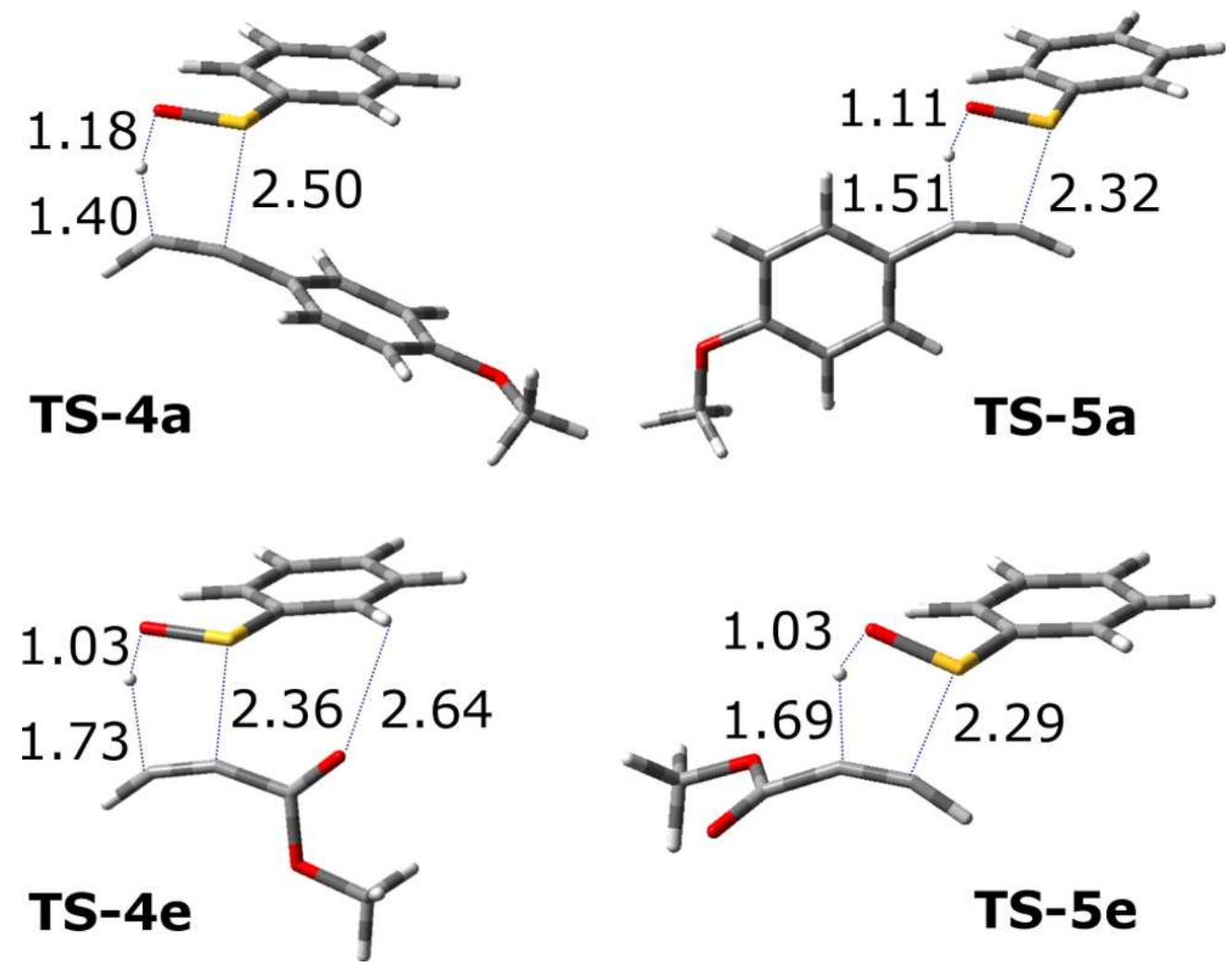

Figure 6. Optimized TSs for the addition of 2 to $3 a$ and 3e. Selected distances are reported in angstrom.

$83 \times 66 \mathrm{~mm}(300 \times 300 \mathrm{DPI})$ 

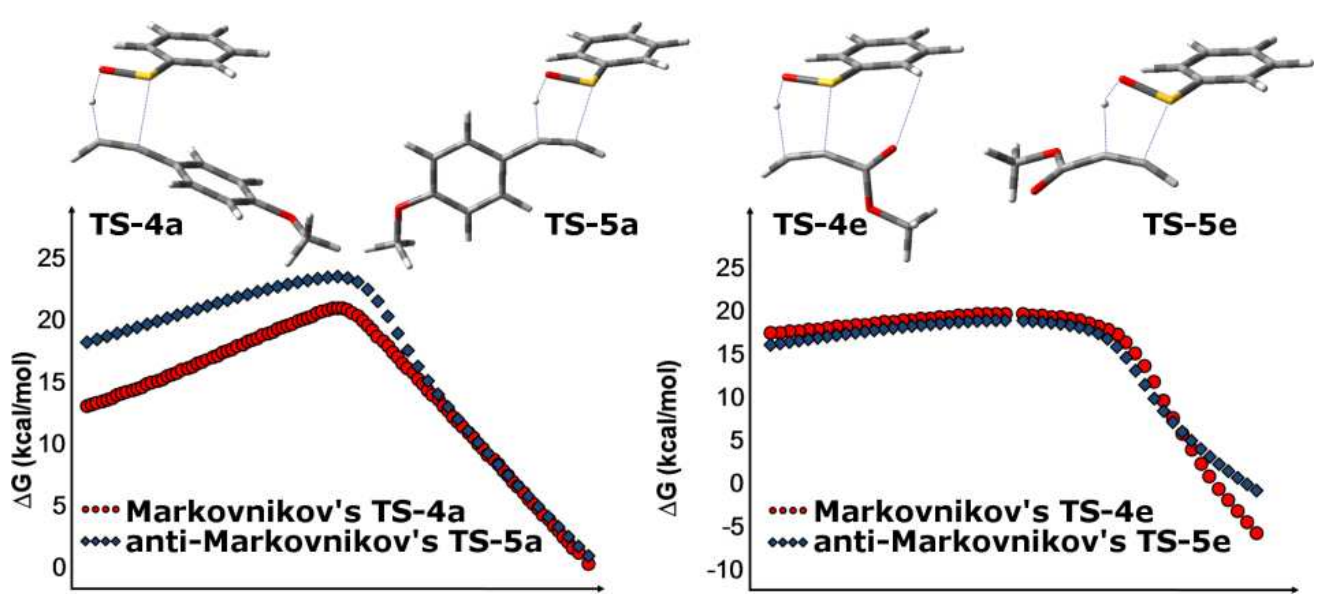

The reaction of benzenesulfenic acid with monosubstituted alkynes was experimentally and theoretically investigated. A model based on the HSAB principle was evaluated for its ability to qualitatively and quantitatively predict the regioselectivity. Kinetics and thermodynamics of the reaction were studied through the computational analysis of the reaction path. $80 \times 35 \mathrm{~mm}(300 \times 300 \mathrm{DPI})$ 